\title{
A novel adhesive complex at the base of intestinal microvilli
}

Christian Hartmann ${ }^{1,2}$, Eva-Maria Thüring ${ }^{1,2}$, Birgitta E. Michels ${ }^{1,2}$, Denise Pajonczyk ${ }^{1,2}$, Sophia Leußink $^{1,2}$, Lilo Greune ${ }^{3}$, Frauke Brinkmann ${ }^{1,2}$, Mark Glaesner-Ebnet ${ }^{1,2}$, Eva Wardelmann ${ }^{4}$, Thomas Zobel ${ }^{5}$, M. Alexander Schmidt ${ }^{3}$, Volker Gerke ${ }^{2,7}$, Klaus Ebnet ${ }^{1,2,6,7, *}$

${ }^{1}$ Institute-associated Research Group "Cell adhesion and cell polarity", ${ }^{2}$ Institute of Medical Biochemistry, ZMBE, University of Münster, D-48149 Münster, Germany

${ }^{3}$ Institute of Infectiology, ZMBE, University of Münster, D-48149 Münster, Germany

${ }^{4}$ Gerhard-Domagk-Institute of Pathology, University Hospital Münster, D-48149 Münster, Germany

${ }^{5}$ Imaging Network Microscopy, University of Münster, D-48149 Münster, Germany

${ }^{6}$ Interdisciplinary Clinical Research Center (IZKF), University of Münster, D-48149 Münster, Germany

${ }^{7}$ Cells-in-Motion Interfaculty Center (CiMIC), University of Münster, D-48419 Münster, Germany

*: author for correspondence

Klaus Ebnet, PhD, Institute-associated Research Group "Cell adhesion and cell polarity", Institute of Medical Biochemistry, ZMBE, University of Münster, Von-Esmarch-Str. 56, D-48149

Münster, Germany

Tel.: +49-(0)251-8352127

FAX: +49-(0)251-8356748

e-mail: ebnetk@uni-muenster.de

ORCID-\#: 0000-0002-0417-7888

Running title: Adhesion molecule TMIGD1 in microvilli

Key words: adhesion molecule, brush border, EBP50, ezrin, TMIGD1 


\section{Abstract}

Intestinal epithelial cells form dense arrays of microvilli at the apical membrane to enhance their functional capacity. Microvilli contain a protocadherin-based intermicrovillar adhesion complex localized at their tips which regulates microvillar length and packaging. Here, we identify a second adhesive complex in microvilli of intestinal epithelial cells. This complex is localized at the basal region of microvilli and consists of the adhesion molecule TMIGD1, the phosphoprotein EBP50 and the F-actin - plasma membrane cross-linking protein ezrin. Ternary complex formation requires unmasking of the EBP50 PDZ domains by ezrin binding and is strongly enhanced upon mutating Ser162 located in PDZ domain 2 of EBP50. Dephosphorylation of EBP50 at S162 is mediated by PP1a, a serine/threonine phosphatase localized at the microvillar base and involved in ezrin phosphocycling. Importantly, the binding of EBP50 to TMIGD1 enhances the dynamic turnover of EBP50 at microvilli in a Ser162 phosphorylation-dependent manner. We identify an adhesive complex at the microvillar base and propose a potential mechanism that regulates microvillar dynamics in enterocytes. 


\section{Introduction}

Intestinal epithelial cells are highly polarized with an apical domain facing the intestinal lumen and a bounded baso-lateral domain that is in contact with adjacent cells and the extracellular matrix. One prominent feature of these cells is a densely packed array of microvilli at their apical domain, collectively known as brush border (BB) (Crawley et al, 2014a; Delacour et al, 2016; Sauvanet et al, 2015b). Microvilli are actin-based structures consisting of $\sim 20-30$ actin filaments that are bundled by actin cross-linking proteins like villin, espin and fimbrin (Crawley et al., 2014a; Sauvanet et al., 2015b). The bundling of the actin filaments is thought to be necessary to generate and focus the forces required for membrane deformation during microvilli formation, which is mediated by actin polymerization at the barbed ends of actin filaments (Claessens et al, 2006; Mooseker et al, 1982).

Microvilli formation is a dynamic process (Gorelik et al, 2003; Klingner et al, 2014; Meenderink et al, 2019; Stidwill et al, 1984). When the BB forms, microvilli are highly motile and initially form sparse clusters (Crawley et al, 2014b; Meenderink et al., 2019). Actin assembly at the barbed ends of the core bundles combined with F-actin treadmilling renders microvilli motile and drives lateral collisions between clusters to form larger clusters which further grow in size and eventually form a BB with microvilli that are maximally packed and uniform in length (Crawley et al., 2014b; Meenderink et al., 2019). Both microvilli clustering during BB formation as well as maximal packing and length uniformity depend on intermicrovillar adhesion mediated by a protocadherin-based adhesive complex which is specifically enriched at the tips of microvilli (intermicrovillar adhesion complex, IMAC). The IMAC is based on trans-heterophilic interaction of protocadherins CDHR2 and CDHR5 which are linked to the underlying actin cytoskeleton through the PDZ domain scaffolding protein USH1C/Harmonin, its binding partner ANKS4B, and the unconventional myosin MYO7B (Crawley et al., 2014b; Crawley et al, 2016). Loss of function of the IMAC results in severe defects in brush border morphology, like a loss of microvillar clustering, reduced microvillar density and increased length variability (Crawley et al., 2014b; Crawley et al., 2016; Pinette et al, 2019; Weck et al, 2016). 
After the establishment of a densely packed BB, microvilli dynamics remain high. In cultured kidney epithelial cells, microvilli undergo phases of growth, steady state, and retraction with an estimated average life cycle of $12.1 \pm 5.6 \mathrm{~min}$ (Gorelik et al., 2003; Loomis et al, 2003). Microvilli dynamics is regulated by ezrin, an actin filament - plasma membrane cross-linking protein ezrin (Bretscher, 1983; Zwaenepoel et al, 2012). Ezrin switches between a closed and an open conformation, regulated by phosphorylation at T567 (Matsui et al, 1999). Phosphorylation T567 of ezrin (Matsui et al., 1999) occurs specifically at the distal tips of microvilli (Hanono et al, 2006; Pelaseyed \& Bretscher, 2018; Viswanatha et al, 2012), the site of active microvillar growth (Crawley et al., 2014a; Sauvanet et al., 2015b). Ezrin T567 phosphocycling is required for apical membrane localization of ezrin as well as microvilli formation (Garbett \& Bretscher, 2012; Viswanatha et al., 2012). How ezrin T567 phosphorylation is restricted to the microvillar tips is poorly understood. Active ezrin interacts with EBP50/NHERF1 (Reczek et al, 1997; Weinman et al, 1995), a PDZ domain-containing scaffolding protein which binds PP1a (Kremer et al, 2015; Zhang et al, 2019), the phosphatase predicted to dephosphorylate ezrin at T567 at the microvillar base (Canals et al, 2012; Viswanatha et al, 2014; Viswanatha et al., 2012).

In this study, we identify a novel adhesive complex at the base of microvilli. This complex consists of the immunoglobulin superfamily (IgSF) member Transmembrane and Immunoglobulin Domain-containing Protein 1 (TMIGD1), EBP50, and ezrin. TMIGD1 directly interacts with EBP50 through a PDZ domain-mediated interaction. This interaction requires the open conformation of EBP50 induced by ezrin binding. PP1 1 -mediated dephosphorylation of EBP50 at S162 localized in the carboxylate binding loop of PDZ2 promotes the interaction of EBP50 with TMIGD1 and enhances the dynamic turnover of EBP50. Our results identify a new adhesive complex localized at the base of microvilli and provide novel insights into the mechanisms which regulate ezrin phosphocycling and microvilli dynamics.

\section{Results}




\section{TMIGD1 is a novel component of the brush border in intestinal epithelial cells}

TMIGD1 is predominantly expressed by epithelial cells of the kidney (Arafa et al, 2015; Hartmann et al, 2020) and of the small intestine (Cattaneo et al, 2011; Zabana et al, 2020). In two colon-derived cell lines, i.e. Caco-2 $\mathrm{BBe}$ cells (Peterson \& Mooseker, 1992) and T84 cells (Murakami \& Masui, 1980) we observed in a fraction of cells an enrichment of TMIGD1 at the apical membrane domain with a staining pattern strongly reminiscent of microvillar localization (Fig. 1A, Suppl. Fig.1). Given this rather unusual localization for an adhesion receptor we performed co-stainings with various microvillar markers. TMIGD1 co-localized with villin and ezrin but showed only little co-localization with Eps8, a microvillar tip-localized F-actin capping and bundling protein (Zwaenepoel et al., 2012) (Fig. 1B). Immunogold electron microscopy (EM) confirmed that TMIGD1 is predominantly localized at the subapical region of microvilli (Fig. 1C) and mostly absent from the distal tips, which have been estimated to span approximately $25 \%$ of microvilli in Caco-2 ${ }_{\text {BBe }}$ cells (Weck et al., 2016). We also analyzed LS174T-W4 cells, a human colon-derived cell line in which a polarized brush border at the single cell level can be induced by doxycycline-regulated expression of the adapter protein STRAD resulting in activation of the polarity kinase LKB1 (Baas et al, 2004). Upon LKB1 activation TMIGD1 was efficiently recruited from the cytoplasm to the brush border, where it showed partial co-localization with ezrin and weak co-localization with Eps8 (Fig. 1D-F). In organoids derived from intestinal crypts TMIGD1 co-localized with villin at the apical membrane domain (Fig. 1G). Together, these findings identified the adhesion molecule TMIGD1 as a novel component of the intestinal brush border localized at the subapical region of microvilli.

\section{TMIGD1 directly interacts with two scaffolding proteins localized at the brush border}

We next sought to identify cytoplasmic interaction partners for TMIGD1. In a yeast-two hybrid screen we isolated a cDNA fragment that covered AA 140-307 of murine E3KARP/NHERF2. The isolated cDNA clone comprised the entire PDZ2 domain of E3KARP (AA 151-231 of murine E3KARP) (Fig. 2A). In vitro binding experiments using the cytoplasmic tail of TMIGD1 fused to GST and an in vitro translated E3KARP construct indicated a direct interaction of 
TMIGD1 and E3KARP, which was abrogated after deleting the PDZ-binding motif (PBM) at the C-terminus of TMIGD1 (Fig. 2B). Mutating the canonical GLGF motif (Doyle et al, 1996) in either of the two PDZ domains of E3KARP (PDZ1: $G_{20} Y G_{23}>$ GYAA; PDZ2: $G_{160} Y_{G} F_{163}>$ GYAA) strongly reduced the interaction, suggesting that both PDZ domains can bind TMIGD1 (Fig. 2C). Co-immunoprecipitation (CoIP) experiments from transfected HEK293T cells indicated that TMIGD1 and E3KARP interact in cells and confirmed that this interaction is mediated by the PBM of TMIGD1 and both PDZ domains of E3KARP (Fig. 2D).

The closest homologue of E3KARP is EBP50 (or NHERF1) (Reczek et al., 1997; Sauvanet et al, 2015a). Similar to E3KARP, EBP50 consists of two PDZ domains and a Cterminal ezrin-binding domain (EBD), is localized at microvilli, and has been implicated in microvilli formation (Garbett \& Bretscher, 2012; Garbett et al, 2010; Garbett et al, 2013; LaLonde et al, 2010; Morales et al, 2004). To test if TMIGD1 also interacts with EBP50, we performed ColP experiments. EBP50 co-immunoprecipitated with TMIGD1 but not with TMIGD1 lacking the PBM (Fig. 3A). Mutating the PDZ domains in EBP50 (PDZ1: G $_{23}$ YGF $_{26}>$ GYAA; PDZ2: $\mathrm{G}_{163} \mathrm{YGF}_{166}$ > GYAA) almost abolished the interaction in both cases (Fig. 3A). To test if this interaction is direct we performed in vitro binding experiments with recombinant proteins. Since EBP50 is autoinhibited in the absence of ezrin (Cheng et al, 2009; Morales et al, 2007; Reczek \& Bretscher, 1998), we performed GST pulldown experiments in the presence of recombinant ezrin, either wildtype (dormant) ezrin (Ezrin/WT) or the constitutively active (open) form of ezrin (Ezrin/T567D). In the presence of Ezrin/WT, EBP50 was not detectable in GST-TMIGD1 precipitates (Fig. 3B). However, in the presence of active ezrin (Ezrin/T567D), EBP50 readily co-precipitated with GST-TMIGD1 (Fig. 3B). Mutating either of the two EBP50 PDZ domains strongly reduced the interaction with TMIGD1 (Fig. 3C). Together, these observations indicate that TMIGD1 directly interacts with EBP50 in a PDZ domain-dependent manner, that both PDZ domains of EBP50 can bind TMIGD1, and that this interactions requires the release of EBP50 autoinhibition by active ezrin (Fig. 3D). 
We next tested if EBP50 and/or E3KARP regulate the localization of TMIGD1 at microvilli. Both EBP50 and E3KARP co-localized with TMIGD1 at polarized brush borders in LS174T-W4 cells (Suppl. Fig. S2A). TMIGD1 localization at the brush border was lost after deletion of the PBM of TMIGD1 (Fig. 4A) indicating a PDZ domain-dependent recruitment to microvilli. Knockdown of either EBP50 or E3KARP alone had only little effect on TMIGD1 recruitment to polarized brush borders (Fig. 4B). Simultaneous knockdown of EBP50 and E3KARP, however, completely abrogated TMIGD1 recruitment to polarized brush borders (Fig. 4B). The combined absence of EBP50 and E3KARP did not change the expression of microvillar key components like ezrin or Eps8 (Supl. Fig. S2B) nor did it prevent the formation of microvilli-containing, Factin-rich and Eps8-positive polarized caps (Supl. Fig. S2C, D). These findings indicate that both EBP50 and E3KARP can recruit TMIGD1, and that one of these two scaffolding proteins is necessary for microvillar localization of TMIGD1.

\section{TMIGD1 regulates the dynamic turnover of EBP50 and E3KARP}

The growth of microvilli is a dynamic process with microvillar lifetimes in a range of 7 to $15 \mathrm{~min}$ (Garbett \& Bretscher, 2012; Gorelik et al., 2003). Proteins regulating microvilli growth and dynamics have high turnover rates. Half-maximal fluoresence recovery after photobleaching (FRAP) are in a range of $30 \mathrm{sec}$ for microvilli proteins such as ezrin, E3KARP or brush border Myosin I (MYOIA) (Coscoy et al, 2002; Garbett \& Bretscher, 2012; Garbett et al., 2013; Tyska \& Mooseker, 2002). The turnover rate of EBP50 is even faster (half-maximal FRAP $5 \mathrm{sec}$ ) and, interestingly, its turnover is regulated by PDZ domain occupancy (Garbett \& Bretscher, 2012; Garbett et al., 2013). To test if TMIGD1 influences the dynamics of EBP50 and E3KARP at microvilli we performed FRAP experiments in JEG-3 cells expressing TMIGD1 under a doxycycline-regulated promoter (Suppl. Fig. S3). JEG-3 cells, a choriocarcinoma-derived cell line, has widely been used as a model to study microvilli formation and dynamics (Garbett \& Bretscher, 2012; Garbett et al., 2010; Garbett et al., 2013; Hanono et al., 2006; Sauvanet et al., 2015a; Viswanatha et al., 2012). The recovery rates for ezrin did not significantly differ in the absence and presence of TMIGD1 expression (Fig. 5A). The recovery rates of both EBP50 
and E3KARP were slightly but significantly reduced in the presence of TMIGD1 expression (EBP50: $P=0.031$, E3KARP: $P=0.026$ ) (Fig. 5B, C). These observations suggest that TMIGD1 reduces the mobility of EBP50 and E3KARP in microvilli, most likely by immobilizing the two proteins at the microvillar membrane.

\section{EBP50 phosphorylation at Ser162 regulates TMIGD1 binding and protein turnover}

EBP50 is a phosphoprotein with numerous phosphorylation sites (Reczek et al., 1997; Vaquero et al, 2017). Several phosphoserine residues are implicated in microvilli assembly, including S162, S280 and S302 which are phosphorylated by PKC (Garbett et al., 2010; Li et al, 2007; Raghuram et al, 2003), and S339 and S240 which are phosphorylated by Cdk1 (Garbett et al., 2010; He et al, 2001). We generated phosphodeficient Ser-to-Ala mutants of these residues in three groups (S162A, S280-302A, S339-340A) and analyzed the interaction of these mutants with TMIGD1 in ColP experiments. The S280-302A and S339-340A mutations did not alter the interaction with TMIGD1 (Fig. 6A). Surprisingly, the S162A mutation significantly enhanced the interaction with TMIGD1 (Fig. 6A) suggesting that the TMIGD1 EBP50 interaction is subject to phosphoregulation by PKC involving S162.

To further explore a PKC-dependent interaction between TMIGD1 and EBP50, we stimulated cells with PMA. EBP50/WT co-immunoprecipitated with TMIGD1 at similar efficiencies without or with PMA stimulation (Fig. 6B). EBP50/S162A, however, coimmunoprecipitated with TMIGD1 at much lower efficiencies after PMA stimulation (Fig. 6B). These findings further suggest that the interaction between TMIGD1 and EBP50 is dynamic and subject to PKC-mediated phosphoregulation.

Intriguingly, S162 of EBP50 is located within PDZ domain 2 and is situated in immediate vicinity of the GLGF motif $\left(\mathrm{G}_{163} \mathrm{YGF}_{166}\right)$ suggesting that its phosphorylation impairs ligand binding. We therefore tested the possibility that TMIGD1 phosphorylation within the PBM could block the interaction with EBP50. We generated phosphomimetic mutants of both potential PKC phosphorylation sites present in the PBM of TMIGD1 (S258D, T260D) and performed in vitro binding experiments. Mimicking phosphorylation of either S258 or T260 strongly impaired 
the interaction with EBP50 (Fig. 6C), suggesting that the interaction of TMIGD1 and EBP50 may be regulated by phosphorylation of amino acids located at the interface between the two interacting molecules.

The function of EBP50 in microvilli formation has been found to depend on its interaction with both ezrin and a hitherto unidentified PDZ1 ligand (Garbett et al., 2010), which suggested the existence of an integral membrane protein at microvilli that tethers the ezrin - EBP50 complex to the membrane. We therefore tested if ezrin is associated with TMIGD1 through EBP50. Since EBP50 associates poorly with full length ezrin, most likely because ezrin undergoes an intramolecular head-to-tail interaction involving the $\mathrm{N}$-terminal FERM domain and the C-terminal $E_{584} A_{585} L_{586}$ motif (Gary \& Bretscher, 1995; Viswanatha et al, 2013), we used a C-terminal truncation mutant of ezrin (ezrin $\left.{ }_{1-583}\right)$ for these experiments. TMIGD1 coimmunoprecipitated with ezrin when EBP50 was present but not when EBP50 was absent (Fig. 6D). The interaction of TMIGD1 and ezrin was enhanced when S162 of EBP50 was mutated to Ala (Fig. 6D). These findings indicated that TMIGD1 exists in a ternary complex with ezrin and EBP50 and suggest that TMIGD1 tethers ezrin to the plasma membrane through EBP50. They also indicate that dephosphorylation of EBP50 at S162 enhances the tethering of the ezrin - EBP50 complex to the membrane by TMIGD1.

EBP50 and ezrin are localized along the entire microvilli but active ezrin characterized by T567 phosphorylation is restricted to the distal tips (Garbett et al., 2013; Hanono et al., 2006). Inactivation of ezrin at the basal region has been proposed to involve dephosphorylation of T567 by protein phosphatase PP1a (Canals et al., 2012; Viswanatha et al., 2014; Viswanatha et al., 2012). Intriguingly, PP1a can directly interact with EBP50 through a conserved VxW/F motif in EBP50 $\left(\mathrm{V}_{257} \mathrm{P}_{258} \mathrm{~F}_{259}\right)$ (Kremer et al., 2015; Zhang et al., 2019) that does not overlap with the ezrin-binding motif $\left(\mathrm{M}_{346}-\mathrm{L}_{358}\right)$ (Terawaki et al, 2006), suggesting that EBP50 could act as a scaffold for both ezrin and PP1 $\alpha$ allowing simultaneous binding and their functional interaction. To address the possibility that PP1 $1 \alpha$ dephosphorylates Ser162 of EBP50, which would promote the interaction with TMIGD1, we performed in vitro dephosphorylation experiments with an EBP50 and recombinant PP1a. We used a GST- 
EBP50 fusion construct that consists of AA95 - 268, thus containing the $\mathrm{S} 162$ residue as the only known PKCa phosphorylation site and in addition the PP1 $\alpha$ binding motif $\left(\mathrm{V}_{257} \mathrm{P}_{258} \mathrm{~F}_{259}\right)$. In line with published data (Li et al., 2007; Raghuram et al., 2003), GST-EBP50/95-268 was strongly phosphorylated by PKCa (Fig. 6E). The S162A mutant was only barley phosphorylated indicating that Ser162 is the only relevant PKCa phosphorylation site in this constuct. Importantly, PP1a completely dephosphorylated S162-phosphorylated EBP50/95268 (Fig. 6E). These observations identify PP1a as a phosphatase that dephosphorylates EBP50 at S162. They suggest that PP1 $\alpha$ localized at the microvillar base might not only serve to dephosphorylate ezrin at T567 to restrict the ezrin phosphocycle to microvillar tips but also to dephosphorylate EBP50 at S162 in PDZ 2 to promote the binding of EBP50 to TMIGD1 and the tethering of the ezrin - EBP50 complex to the membrane.

Previous observations indicate that EBP50 PDZ domain occupation increases the dynamic behaviour of EBP50 at microvilli (Garbett \& Bretscher, 2012; Garbett et al., 2013). To test if the P-S162 regulation of the TMIGD1 - EBP50 interaction affects the dynamics of EBP50 turnover at microvilli, we performed FRAP experiments with EBP50/S162A in the absence and presence of TMIGD1. Surprisingly, as opposed to its influence on EBP50/WT, TMIGD1 accelerated the recovery of EBP50/S162 after photobleaching ( $P=0.0007)$ (Fig. 6F) suggesting that the binding of S162-dephosphorylated EBP50 to TMIGD1 increases its dynamics at microvilli. These findings suggest that TMIGD1 represents an integral protein at the microvillar base with the capacity to increase the turnover of EBP50 by binding to EBP50 PDZ domains, which has previously been postulated to exist (Garbett \& Bretscher, 2012). Altogether, these findings suggest a model in which dephosphorylation of EBP50 at $\mathrm{S} 162$ by EBP50-bound PP1a promotes the interaction of the ezrin - EBP50 complex with TMIGD1. At the same time, most likely as a result of PP1 1 -mediated dephosphorylation of ezrin at T567 which results in ezrin inactivation, the ezrin - EBP50 complex is destabilized resulting in the closed EBP50 conformation, reduced EBP50 binding to TMIGD1 and thus increased turnover of EBP50. 
Microvilli contain a protocadherin-based adhesive complex at their tips, the intermicrovillar adhesion complex (IMAC) (Crawley et al., 2014b). Since TMIGD1 has been described as adhesion molecule (Arafa et al., 2015), we tested its adhesive properties in more detail. Ectopically expressed TMIGD1 increased aggregate formation of HEK293T cells (Fig. 7A), indicating that TMIGD1 can promote homotypic cell-cell adhesion, as oberved before (Arafa et al., 2015). To test if TMIGD1 is a homophilic adhesion receptor, we performed ColP experiments with differentially tagged TMIGD1 constructs. Untagged TMIGD1 was efficiently immunoprecipitated with Flag-EGFP-TMIGD1 (Fig. 7B). Untagged TMIGD1 was also immunprecipitated with a Flag-EGFP-TMIGD1 construct in which the cytoplasmic domain of TMIGD1 was replaced by the cytoplasmic domain of JAM-A (Fig. 7B). Vice versa, an untagged TMIGD1 lacking the complete cytoplasmic domain was efficiently immunoprecipitated with Flag-EGFP-TMIGD1 (Fig. 7B). These findings indicate that TMIGD1 undergoes homophilic interaction through its extracellular domain, either in cis or in trans. To test if this interaction can occur in trans, we performed aggregation assays with fluorescently labelled beads coated with the extracellular domain (ECD) of TMIGD1. TMIGD1-coated beads formed aggregates (Fig. 7C) indicating a trans-homophilic adhesive activity of TMIGD1 that is sufficient to support aggregation, a property that is typical for strong adhesion molecules like cadherins and various IgSF members (Honig \& Shapiro, 2020), and that has recently been described for heterophilic protocadherin interactions at the microvillar tips (Crawley et al., 2014b). A model incorporating our findings on TMIGD1 into the existing model on the regulation of microvilli dynamics is depicted in Fig. 8.

\section{Discussion}

In this study we identify a novel adhesion complex in microvilli of enterocytes. The adhesion receptor present in this complex is the IgSF member TMIGD1 which directly interacts with two microvilli-localized PDZ domain-containing scaffolding proteins, EBP50/NHERF1 and E3KARP/NHERF2. The interaction with EBP50 requires ezrin resulting in a ternary complex in which ezrin is linked to membrane-localized TMIGD1 through EBP50. Both ezrin and EBP50 
play critical roles in microvilli formation and dynamics (Garbett \& Bretscher, 2012; Garbett et al., 2010; LaLonde et al., 2010; Viswanatha et al., 2012). Recent studies described TMIGD1 as component of the apical membrane of enterocytes whose absence results in a defective BB membrane (De La Cena et al, 2020; Zabana et al., 2020). Our findings thus identify TMIGD1 as part of an adhesive complex at the micorvillar base and describe a mechanism though which TMIGD1 regulates microvilli formation.

TMIGD1 has been described to be predominantly expressed by epithelial cells of the kidney and of the intestine (Arafa et al., 2015; Cattaneo et al., 2011; Meyer et al, 2018). Its expression is downregulated during malignant transformation and during inflammation both in the kidney (Arafa et al., 2015; Meyer et al., 2018) and in the intestine (Cattaneo et al., 2011; Lee et al, 2015; Mojica \& Hawthorn, 2010; Roberts et al, 2015; Zabana et al., 2020) suggesting a tumor-suppressive function. The reduction and/or loss of TMIGD1 expression during cellular transformation might explain the low expression levels of TMIGD1 in many cell lines derived from kidney or intestine (Cattaneo et al., 2011; Meyer et al., 2018) and might also be responsible for our observation of TMIGD1 expression in only a fraction of colon carcinomaderived Caco-2 and T84 cells (Fig. 1A, Suppl. Fig. S1).

We find that TMIGD1 directly interacts with two scaffolding proteins at microvilli, EBP50 and E3KARP, and that either of the two is required for microvillar localization of TMIGD1. In both cases, the interaction is direct and mediated by the PDZ domain-binding motif of TMIGD1 (-SETAL). We observed for both EBP50 and E3KARP that inactivating either of the two PDZ domains strongly impairs TMIGD1 binding (Fig. 2, 3). We interpret this in a way that both PDZ domains can bind TMIGD1 and that ligand binding to either of the two PDZ domains may influence the accessibility of the other PDZ domain for TMIGD1. In line with this assumption, autoinhibition of EBP50 mediated by its C-terminal PBM (-LFSNL) interacting with PDZ2 masks both PDZ domains (Morales et al., 2007), and vice versa, the release of autoinhibition by ezrin binding to the EB region renders both PDZ domains accessible for ligands ( $\mathrm{Li}$ et al, 2009). Also, studies with EBP50 phosphomimicking mutants showed that ligand binding to PDZ2 blocks PDZ1 accessibility (Garbett et al., 2010). This coordinated regulation of PDZ 
domain accessibility is most likely regulated by an allosteric mechanism in which ligand binding induces a long range conformational change of EBP50 (Bhattacharya et al, 2010; Bhattacharya et al, 2019; Li et al., 2009). An interaction of both PDZ domains with the same ligand has also been found for the interaction of EBP50 with the cystic fibrosis transmembrane conductance regulator (CFTR) as well as for the interaction of E3KARP with PTEN (Short et al, 1998; Takahashi et al, 2006).

The interaction of TMIGD1 with EBP50 is enhanced when S162 of EBP50 is mutated to Ala, strongly suggesting that Ser162 phosphorylation inhibits the interaction. Ser162 is located in PDZ2 of EBP50 and immediately precedes the canonical GLGF motif present in the carboxylate-binding loop of PDZ domains $\left(\mathrm{G}_{163} \mathrm{YGF}_{166}\right.$ in EBP50 PDZ2) (Doyle et al., 1996). Similarly positioned phosphoserine residues with negative impact on ligand binding have been identified in PDZ1 of DLG1/SAP-97 (S S $\left.32_{2} \mathrm{GLGF}_{236}\right)$ and in PDZ1 of DLG4/PSD-95 (S $\left.{ }_{73} \mathrm{GLGF}_{77}\right)$, (Gardoni et al, 2006; Mauceri et al, 2007; Pedersen et al, 2017). In addition, the interaction of EBP50 with the cystic fibrosis transmembrane conductance regulator (CFTR) has been described to be negatively regulated by S162 phosphorylation of EBP50 (Raghuram et al., 2003). Site-specific phosphorylation of both PDZ domains and the PBMs in their ligands has been described to fine-tune and to regulate specificity of PDZ domain - ligand interactions (Liu \& Fuentes, 2019). As a further evidence for a phosphoregulation of the EBP50 - TMIGD1 interaction, we found that mimicking phosphorylation of two residues present in the PBM of TMIGD1 prevents the interaction with EBP50. Our observations thus suggest that the TMIGD1 - EBP50 interaction is regulated by phosphorylation of residues localized at key positions in the PDZ domain - PDZ ligand interface thus allowing a rapid and dynamic regulation of the interaction.

We find that PKCa-phosphorylated S162 of EBP50 is dephosphorylated by PP1a. EBP50 contains a PP1 binding motif in the linker region between PDZ2 and the EBD and acts as scaffold for PP1a (Kremer et al., 2015; Zhang et al., 2019). EBP50-bound PP1a dephosphorylates Ser290 of EBP50, a major phosphorylation site for GRK6A (Hall et al, 1999; Zhang et al., 2019) which, however, is not involved in microvilli formation (Garbett et al., 2010). 
Intriguingly, PP1 $\alpha$ has also been postulated to be localized at the basal region of microvilli and to dephosphorylate ezrin at T567 to restrict ezrin activity to the distal tips of microvilli (Canals et al., 2012; Viswanatha et al., 2014; Viswanatha et al., 2012). Our new observations suggest that EBP50-associated PP1a might not only serve to inactivate ezrin but at the same time to promote the interaction of EBP50 with TMIGD1. TMIGD1 localized at the subapical region of microvilli could thus serve to tether the ezrin - EBP50 - PP1 1 complex to the membrane in the subapical region of microvilli. In this complex, PP1a would be able to dephosphorylate EBP50associated ezrin at T567 resulting in ezrin inactivation. The different binding sites in EBP50 for TMIGD1 (PDZ1, AA 14-94 and PDZ2, AA 154 - 234), PP1a (AA 257-259) (Zhang et al., 2019) and ezrin (AA 340-358) (Cheng et al., 2009) would most likely allow a simultaneous interaction of all three components with EBP50.

This model of a tethering function of TMIGD1 for the ezrin - EBP50 - PP1a complex thereby inactivating ezrin receives further support from two lines of evidence. First, the ezrin EBP50 interaction is regulated by EBP50 PDZ domain occupation. EBP50 with intact PDZ domains interacts poorly with ezrin and has a rapid turnover at microvilli (Garbett \& Bretscher, 2012). Inactivating the two PDZ domains increases the interaction with ezrin and at the same time stabilizes EBP50 at microvilli (Garbett \& Bretscher, 2012; Garbett et al., 2013). These observations indicated that the binding of EBP50 to a membrane protein through one or both of its PDZ domains destabilizes its interaction with ezrin. Second, the ezrin - EBP50 interaction is regulated by a feedback mechanism. The binding of active ezrin to EBP50 not only stabilizes active EBP50 but also active ezrin itself (Terawaki et al., 2006). Dephosphorylation of ezrin at T567 by EBP50-bound PP1a would thus most likely negatively feed back into EBP50's ability to stabilize active ezrin resulting in a further destabilization of active ezrin. As a result, inactive ezrin would be no longer capable to maintain EBP50 in its open conformation which may result in reduced binding of EBP50 to PDZ domain ligands in the membrane and increased EBP50 turnover. As predicted from these findings, we observed an increase in the turnover of EBP50/S162A in microvilli in the presence of TMIGD1 (Fig. 6). We speculate that the strong TMIGD1 binding to the S162-unphosphorylated PDZ2 of EBP50 could act as allosteric signal 
that might enhance the negative feedback regulation of ezrin and EBP50. Thus, tethering the ezrin - EBP50 complex by TMIGD1 to the plasma membrane in the subapical region of microvilli, triggered by dephosphorylation of EBP50 at S162 by EBP50-bound PP1a, would contribute to the inactivation of both ezrin and EBP50 and result in increased EBP50 turnover (see Fig. 8 for a model).

A still unexplored question relates to the mechanism by which TMIGD1 is restricted to the lower region of microvilli. The localization of TMIGD1 overlaps with the localization of E3KARP, which localizes to the lower two thirds of microvilli in JEG-3 cells (Garbett et al., 2013). Our findings of a direct interaction of TMIGD1 with E3KARP thus opens the possibility that E3KARP is responsible for the localization of TMIGD1 at the subapical region of microvilli. This possibility is appealing since the interaction of TMIGD1 with EBP50 may be very dynamic and regulated by active ezrin as well as by PKC- and PP1a-mediated phosphorylation and dephosphorylation, respectively, of EBP50. A stable localization of TMIGD1 at the subapical region of microvilli combined with a dynamic association with the active ezrin - EBP50 complex could be achieved if TMIGD1 is engaged in trans-homophilic interactions between adjacent microvilli. Our observations indicate that the extracellular domain of TMIGD1 promotes bead aggregation, strongly suggesting trans-homophilic adhesive activity of TMIGD1. Therefore, one could imagine a scenario in which two TMIGD1 molecules present in a trans-interacting dimer interact differently with EBP50 and E3KARP proteins on opposing microvilli. The E3KARP interaction could restrict the dimer to the subapical region whereas the EBP50 interaction could regulate the dynamic interaction of the ezrin - EBP50 complex with the membrane.

Recent observations indicate that microvilli organization is regulated by an intermicrovillar adhesion complex (IMAC) localized at the tips of microvilli (Crawley et al., 2014b). This complex consists of the protocadherins cadherin-related family member (CDHR) 2 and CDHR5 which trans-heterophilically interact through their extracellular domains and which are linked to a cytoplasmic protein complex consisting of the PDZ domain protein USH1C/Harmonin, Myosin-7b and ankyrin repeat and SAM domain-containing protein 4B (ANKS4B) (Crawley et 
al., 2014b; Crawley et al., 2016; Weck et al., 2016). This complex regulates the packing density of microvilli (Crawley et al., 2014b). Our observations that TMIGD1 undergoes transhomophilic interaction, and that TMIGD1 interacts with EBP50 and E3KARP proteins which act as scaffolds for ezrin and PP1a suggest that TMIGD1 forms a second intermicrovillar adhesion complex. We hypothesize that the function of this adhesion complex could be to inactivate ezrin at the subapical region of microvilli thereby restricting ezrin activity to the distal tip region (Fig. 8). Future studies with TMIGD1 knockout mice will be important to analyze the function of TMIGD1 in microvilli formation and dynamics.

\section{Materials and Methods}

\section{Cell culture and transfections}

Caco-2 cells (clone C2BBe1, ATCC-CRL-2102) were grown in DMEM (Sigma-Aldrich (SA) \#D5671), 10\% FCS, 1\% non-essential amino acids (NEAA), $10 \mu \mathrm{g} / \mathrm{ml}$ human transferrin, $2 \mathrm{mM}$ L-glutamine (L-Glu), $100 \mathrm{U} / \mathrm{ml}$ penicillin and $100 \mathrm{U} / \mathrm{ml}$ streptomycin (Pen/Strep, Biochrom, Berlin). Upon splitting, cells were seeded at $4.5 \times 10^{3}$ cells $/ \mathrm{cm}^{2}$. Cells were subcultured after reaching approximately $50 \%$ of confluency under routine culture conditions to prevent differentiation. T84 cells were grown in DMEM/F-12 1:1 mixture (SA \# 6421), 10\% FCS, 1\% NEAA, $10 \mu \mathrm{g} / \mathrm{ml}$ human transferrin, $2 \mathrm{mM} \mathrm{L-Glu,} 100 \mathrm{U} / \mathrm{ml}$ Pen/Strep. LS174T-W4 cells are human colon-derived epithelial cells stably transfected with a constitutive LKB1 and a tetracycline (tet)-controlled STRAD expression vector in which LKB1 activation can be regulated by tet-induced STRAD expression (Baas et al., 2004). Cells were kindly provided by Lucas J. M. Bruurs and Johan L. Bos, Oncode Institute, University Medical Center Utrecht, Utrecht, The Netherlands. Cells were maintained in RPMI 1640 medium (Merck \#F1215), 10\% tetracycline-free FCS (Clontech/TaKaRa, \#631106), 2 mM L-Glu, 100 U/ml Pen/Strep. Expression of STRAD and the concomitant activation of LKB1 was induced by adding doxycycline $(1 \mu \mathrm{g} / \mathrm{ml})$ for at least $16 \mathrm{~h}$. LS174T-W4 cells with a stable KD of EBP50 or E3KARP 
were generated by lentiviral transduction with either EBP50- or E3KARP shRNAs-expressing plasmids followed by selection in medium containing $3 \mu \mathrm{g} / \mathrm{ml}$ puromycin. EBP50/E3KARP double KD LS174T-W4 cells were generated by lentiviral transduction of stable single KD cells with plasmids encoding shRNAs of the respective homolog followed by selection in medium containing $6 \mu \mathrm{g} / \mathrm{ml}$ puromycin for 3 weeks. Single and double knockdown efficiencies were confirmed by western blot analysis (Suppl. Fig. S2B). JEG-3 cells (ATCC-HTB-36) were grown in MEM (Gibco, \#51200-046), 10\% FCS, 2 mM L-Glu, 1mM Na-pyruvate (Merck \#L0473), 100 $\mathrm{U} / \mathrm{ml}$ Pen/Strep. For live cell imaging, JEG-3 cells were maintained in phenol red-free MEM (ThermoFisher \#51200038) supplemented with the same additives and in addition $20 \mathrm{mM}$ HEPES. JEG-3 cells stably expressing hTMIGD1 from a doxycycline-regulated promoter were generated by transducing JEG-3 cells with a plnducer21-Puro plasmid vector (kindly provided by Dr. T. Weide, Department of Internal Medicine D, Division of Molecular Nephrology, University Hospital Münster, Germany) encoding hTMIGD1. Transduced cells were selected in medium containing $3 \mu \mathrm{g} / \mathrm{ml}$ puromycin (Santa Cruz \#sc-108071A) and subcloned by limiting dilution. Inducible expression of TMIGD1 was confirmed by western blot and IF analysis (Suppl. Fig. S3). HEK293T cells (ATCC-CRL-2316) were grown in DMEM containing 10\% FCS, 1\% NEAA, 2 mM L-Glu, $100 \mathrm{U} / \mathrm{ml}$ Pen/Strep.

Transient transfections of cDNAs were performed using Lipofectamine 2000 (ThermoFisher Scientific, \#11668-019) and X-Fect (Xfect ${ }^{\text {TM }}$ Transfection Reagent Clontech/TaKaRa \#631318), according to manufacturer's instructions. Lentiviral particles for the generation of stably transfected cell lines expressing either shRNAs (EBP50, E3KARP) or hTMIGD1 cDNAs were generated by co-transfection of HEK293T cells with the lentiviral vector and the packaging vectors psPAX2 and pMD2.G (kindly provided by Dr Didier Trono, Addgene plasmids 12260 and 12259) in a ratio of 3:2:1 into HEK293T cells. Lentiviral transduction of cells was performed as described (Tuncay et al, 2015). The following shRNAs were used: hEBP50/hNHERF1 shRNA in pLKO.1 (5'- CCTAGACTTCAACATCTCCCT -3', Dharmacon \#TRCN0000043736), hE3KARP/hNHERF2 shRNA in pLKO.1 (5'GATGAACACTTCAAGCGGCTT -3', Dharmacon \#TRCN0000043707). 


\section{Expression vectors}

The following constructs were used. Flag-TMIGD1 constructs in pFlag-CMV-1 (N-terminal Flag tag, Sigma-Aldrich, Munich, Germany): hTMIGD1 without signal peptide (AA 30-262) and hTMIGD1 without signal peptide lacking the PDZ domain binding motif (hTMIGD1/A5, AA 30258). TMIGD1 constructs in plnducer21-Puro: hTMIGD1 full length (AA1-262). TMIGD1 constructs in pcDNA3 (Invitrogen): hTMIGD1 full length (AA1-262), hTMIGD1 lacking the PDZ domain binding motif (hTMIGD1/L5, AA 1-258), hTMIGD1 lacking the cytoplasmic domain (hTMIGD1/ACP, AA 1-241). Flag-tagged TMIGD1-EGFP constructs in pKE1079 (Hartmann et al., 2020): EGFP-hTMIGD1 (AA 30-262, EGFP inserted between AA211 and AA212 of TMIGD1); EGFP-TMIGD1-JAM-A ( $\mathrm{NH}_{2}$-TMIGD1-30-211-EGFP-JAM-A-231-299-COOH). GST-tagged TMIGD1 constructs in pGEX-4T-1 (GE Healthcare): GST-TMIGD1 (hTMIGD1 cytoplasmic tail (AA 242-262); GST-TMIGD1/A5: hTMIGD1 cytoplasmic tail lacking the PDZ domain binding motif (AA 242-257). GST-TMIGD1/S258D (hTMIGD1 cytoplasmic tail (AA 242262_S 258 D); GST-TMIGD1/S260D (hTMIGD1 cytoplasmic tail (AA 242-262_S 260 D). TMIGD1 constructs in yeast-two hybrid vector pBTM116 (Keegan \& Cooper, 1996): pBTM116-TMIGD1 (cytoplasmic tail of hTMIGD1, AA 241-262). TMIGD1-Fc fusion constructs in pcDNA3-hlgG): hTMIGD1-Fc (extracellular domain of hTMIGD1, AA 1 - 222).

EBP50/NHERF1 constructs in pKE081myc (N-terminal myc tag, (Ebnet et al, 2000): hEBP50 full length (hEBP50, AA 2-358), hEBP50 with mutated PDZ domain 1 (hEBP50_P1M, AA 1-358_ $\mathrm{G}_{25} A F_{26} \mathrm{~A}$ ), hEBP50 with mutated PDZ domain 2 (hEBP50_P2M, AA 1 358_G $\left.{ }_{165} A F_{166} A\right)$. EBP50 constructs in pEGFP-C3 (Clontech): hEBP50 full length (hEBP50, AA1-358), hEBP50 with mutated PDZ domain 1 (hEBP50_P1M, AA 1-358_G ${ }_{25} A F_{26} A$ ), hEBP50 with mutated PDZ domain 2 (hEBP50_P2M, AA 1-358_G $\left.{ }_{165} A F_{166} A\right)$. The same EBP50 constructs containing mutations in the shRNA target site (5'CCTgGAtTTtAAtATaTCaCT -3') were generated. hEBP50 with mutations in serine phosphorylation sites: hEBP50_S ${ }_{162} A$ (AA 1-358_S $\left.{ }_{162} A\right)$, hEBP50_S ${ }_{280} A S_{302} A$ (AA 1- 
358_S $\left.{ }_{280} A S_{302} A\right), h E B P 50 \_S_{339} A S_{340} A\left(A A 1-358 \_S_{339} A S_{340} A\right)$. GST-hEBP50 in pGEX-6P-2 (GE Healthcare): GST-hEBP50/WT (AA95-168), GST-hEBP50_S ${ }_{162} A\left(A A 95-168 \_S_{162} A\right)$.

E3KARP/NHERF2 constructs in pKE081myc: hE3KARP full length (hE3KARP, AA 2337), hE3KARP with mutated PDZ domain 1 (hE3KARP_P1M, AA 2-337_G ${ }_{22} A F_{23} A$ ), hE3KARP with mutated PDZ domain 2 (hE3KARP_P2M, AA 2-337_G ${ }_{162} A F_{163} A$ ). E3KARP constructs in pKE1400 (with N-terminal triple-Flag tag): hE3KARP PDZ domains 1 and 2 (FlagE3KARP/PDZ1-2, AA 2-277). E3KARP constructs in pEGFP-C3 (Clontech): hE3KARP full length (hE3KARP, AA 2-337), hE3KARP with mutated PDZ domain 1 (hE3KARP_P1M, AA 2337_ $\mathrm{G}_{22} \mathrm{AF}_{23} \mathrm{~A}$ ), hE3KARP with mutated PDZ domain 2 (hE3KARP_P2M, AA 2337_ $\left.\mathrm{G}_{162} A \mathrm{~F}_{163} \mathrm{~A}\right)$. Identical E3KARP constructs containing mutations in the shRNA target site (5'- GAcGAgCAtTTtAAaCGctTc -3') were also generated.

Ezrin constructs in pET-28a(+) (N-terminal hepta-His tag, Novagen, Madison, WI): hEzrin wildtype (His-Ezrin/WT, AA 1-586), hEzrin with mutated T567 phosphorylation site (HisEzrin/ $T_{567} \mathrm{D}, \mathrm{AA}$ 1-586_- $\left.{ }_{567} \mathrm{D}\right)$. Ezrin constructs in pEGFP-C2 (Clontech): hEzrin wildtype (EGFP-Ezrin/WT, AA 1-586). Ezrin constructs in pcDNA3: hEzrin/ $\triangle 3$ (hEzrin AA 1-583).

JAM-A and Coxsackie- and Adenodvirus Recptor (CAR) constructs in pcDNA3: mJAMA (AA 1 - 300), mCAR (AA 1-365). GST-JAM-A, GST-JAM-B and GST-JAM-C constructs containing the cytoplasmic domains of JAM-A, JAM-B and JAM-C fused to GST as well as JAM-B-FC and JAM-C-FC fusion constructs containing the extracellular domains of JAM-B and JAM-C have been described before (Ebnet et al, 2003).

\section{Antibodies and reagents}

The following antibodies were used in this study: rabbit pAb anti-TMIGD1 (Sigma-Aldrich \#HPA021946); rabbit pAb anti-TMIGD1 (proteintech \# 27174-1 AP); rabbit pAb anti-EBP50 (ThermoFisher \#PAI-090); rabbit pAb anti-NHERF1/EBP50 (Novus \#300-536); rabbit pAb antiSLC9A32 (NHERF2/E3KARP) (Sigma Aldrich \# HPA001672); mouse mAb anti-Ezrin (BD-TL \#610602), rabbit mAb anti-Phospho-Thr567-Ezrin (CST \#3726), rabbit pAb anti-PhosphoThr567-Ezrin (CST \#3141), mouse mAb anti-Villin (SantaCruz \#sc-58897); mouse mAb anti- 
Eps8 (BD-TL \#610143); mouse mAb anti-ZO-1 (BD-TL \#610966); mouse mAb anti-a-Tubulin (Sigma-Aldrich, clone B-5-1-2, \#T5168); mouse mAb anti-Flag M2 (Sigma-Aldrich \#F1804); rabbit pAb anti-Flag (Sigma-Aldrich \#F7425); goat pAb anti-Myc (SantaCruz \#sc-789G); mouse mAb anti-Myc 9E10 (Evan et al, 1985). Rabbit anti-TMIGD1 pAbs Affi1662/1663 was generated by immunizing rabbits with a fusion protein consisting of the extracellular domain of hTMIGD1 fused to the Fc region of human IgG, as described previously (Rehder et al, 2006). The antibodies were affinity-purified by adsorption at the antigen covalently coupled to cyanogen bromide $(\mathrm{CNBr})$-activated sepharose beads (Amersham Biosciences Europe, Freiburg, Germany). Antibodies directed against the Fc part were depleted by adsorption at human IgG coupled to CNBr-activated sepharose beads. Affinity-purified antibodies were dialyzed against PBS. Secondary antibodies and fluorophore-conjugated antibodies: Fluorophore-conjugated antibodies for Western blotting: IRDye 800CW Donkey anti-Rabbit IgG (LI-COR Biosciences \#926-32213), IRDye 680CW Donkey anti-mouse IgG (LI-COR Biosciences \#926-68072). Fluorophore-conjugated secondary antibodies for ICC: Donkey anti-Mouse IgG $(H+L)$ Alexa Fluor 594 (ThermoFisher Scientific \#A-21203); Donkey antiRabbit IgG $(\mathrm{H}+\mathrm{L})$ Alexa Fluor 594 (ThermoFisher Scientific \#A-21207); Donkey anti-Rabbit $\lg G(H+L)$ Alexa Fluor 488 (ThermoFisher Scientific \#A-21206); Donkey anti-Mouse IgG $(H+L)$ Alexa Fluor 488 (Dianova/Jackson ImmunoResearch Europe Ltd \#715-545-150); Donkey antiMouse IgG $(\mathrm{H}+\mathrm{L})$ Alexa Fluor 647 (Dianova/Jackson ImmunoResearch Europe Ltd \#715-605$150)$-conjugated, highly cross-adsorbed secondary antibodies. The following reagents were used: Doxycycline (SA \#D9891), collagen type I (rat tail type 1 collagen, Advanced BioMatrix \#5163), lysozyme (SA \#L6876), imidazole (Carl Roth \#3899), TRITC-Phalloidin (SA \#P1951), CytoPainter Phalloidin-iFluor 647 (Abcam \#176759), Phorbol 12-myristate 13-acetate (PMA) (SA \#P8139), [Y- $\left.{ }^{32} \mathrm{P}\right] A T P$ (3000 Ci/mmol, 10 mCi/ml, Hartmann Analytic $\mathrm{GmbH}$, Braunschweig, Germany, \# SCP-301), PKCa (Eurofins Discovery, Cell L'Evescault, France, \#14-484), PKC lipid activator (MerckMillipore \#20-133), PP1a (Eurofins \#14-595).

\section{Yeast Two-hybrid Screen}


Yeast two-hybrid screening experiments were performed essentially as described (Ebnet et al., 2000). Briefly, the Saccharomyces cerevisiae reporter strain L40 expressing a fusion protein between LexA and the cytoplasmic tail of TMIGD1 (AA 241-262) was transformed with $250 \mu \mathrm{g}$ of DNA derived from a day 9.5/10.5 mouse embryo cDNA library (Hollenberg et al, 1995) according to the method of Schiestl and Gietz (Schiestl \& Gietz, 1989). The transformants were grown for $16 \mathrm{~h}$ in liquid selective medium lacking tryptophan, leucine (SD$\mathrm{TL}$ ) to maintain selection for the bait and the library plasmid, then plated onto synthetic medium lacking tryptophan, histidine, uracil, leucine, and lysine (SD-THULL) in the presence of $1 \mathrm{mM}$ 3-aminotriazole. After 3 days at $30{ }^{\circ} \mathrm{C}$, large colonies were picked and grown for additional three days on the same selective medium. Plasmid DNA was isolated from growing colonies using a commercial yeast plasmid isolation kit (DualsystemsBiotech, Schlieren, Switzerland). To segregate the bait plasmid from the library plasmid, yeast DNA was transformed into E. coli HB101, and the transformants were grown on M9 minimal medium lacking leucine. Plasmid DNA was then isolated from E. coli HB101 followed by sequencing to determine the nucleotide sequence of the inserts.

\section{Immunoprecipitation and Western blot analysis}

For immunoprecipitations, cells were lysed in lysis buffer $(25 \mathrm{mM}$ TrisHCl, $\mathrm{pH} 7.4,1 \%(\mathrm{v} / \mathrm{v})$ Nonidet P-40 (NP-40, AppliChem, Darmstadt, Germany), $150 \mathrm{mM} \mathrm{NaCl}$, protease inhibitors (Complete Protease Inhibitor Cocktail; Roche, Indianapolis, IN), 5\% glycerol ()AppliChem \#A2926) and phosphatase inhibitors (PhosSTOPTM, Roche, Indianapolis, IN), 2 mM sodium orthovanadate) for 20 min with overhead rotation at $4^{\circ} \mathrm{C}$ followed by centrifugation $(15.000$ rpm, $20 \mathrm{~min}$ at $4^{\circ} \mathrm{C}$ ). Postnuclear supernatants were incubated with $3 \mu \mathrm{g}$ of antibodies coupled to protein A- or protein G-Sepharose beads (GE Healthcare, Solingen, Germany) for $4 \mathrm{~h}$ at $4^{\circ} \mathrm{C}$. Beads were washed five times with lysis buffer, bound proteins were eluted by boiling in 3x SDS-sample buffer/150 mM DTT. Eluted proteins were separated by SDS-PAGE and analyzed by Western blotting with near-infrared fluorescence detection (Odyssey Infrared 
Imaging System Application Software Version 3.0 and IRDye 800CW-conjugated antibodies; LI-COR Biosciences, Bad Homburg, Germany).

\section{Purification of recombinant His-tagged proteins}

(His) ${ }_{6}$-tagged ezrin and $(\mathrm{His})_{6}$-tagged ezrin T567D was expressed in E. coli cells (strain BL21(DE3)pLysS). Transformed bacteria were grown to an $\mathrm{OD}_{600}$ of 0.6 at $37^{\circ} \mathrm{C}$, expression of recombinant proteins was induced by incubating cells with isopropyl $\beta-D-1-$ thiogalactopyranoside (IPTG, $1 \mathrm{mM}$ ) for 4 to $5 \mathrm{~h}$ at $37{ }^{\circ} \mathrm{C}$. Cells were harvested by centrifugation (4000 $\times$ g, $15 \mathrm{~min}$ ) and resuspended in ice-cold lysis buffer $\left(50 \mathrm{mM} \mathrm{NaH} \mathrm{PO}_{4}\right.$, $\mathrm{pH}$ 8, $300 \mathrm{mM} \mathrm{NaCl}, 10 \mathrm{mM}$ imidazole, $10 \mathrm{mM}$ EDTA, $10 \mathrm{mM} \beta$-mercaptoethanol, $1 \mathrm{mM}$ PMSF). Cells were lysed by 3 freeze-thaw (liquid nitrogen $-37^{\circ} \mathrm{C}$ waterbath) cycles, incubation with $1 \mathrm{mg} / \mathrm{ml}$ lysozyme for $30 \mathrm{~min}$ on ice followed by sonication (directional cycle 50 , output control 5 for $35 \mathrm{~s}, 3 \mathrm{x})$. After centrifugation $(50.000 \times \mathrm{g}, 45 \mathrm{~min})$, the supernatant was applied to a Ni-NTA-agarose column (SA \#P6611) pre-equilibrated with lysis buffer and incubated for 1 $\mathrm{h}$ at $4^{\circ} \mathrm{C}$ under gentle rotation. After washing with washing buffer $\left(50 \mathrm{mM} \mathrm{NaH}_{2} \mathrm{PO}_{4}, \mathrm{pH} 8,300\right.$ $\mathrm{mM} \mathrm{NaCl}, 20 \mathrm{mM}$ imidazole) His-tagged ezrin constructs were eluted with elution buffer (50 $\mathrm{mM} \mathrm{NaH}_{2} \mathrm{PO}_{4}, 300 \mathrm{mM} \mathrm{NaCl}, 250 \mathrm{mM}$ imidazole) and dialyzed against PBS. Protein solutions were adjusted to $50 \%(\mathrm{v} / \mathrm{v})$ glycerol and stored at $-20^{\circ} \mathrm{C}$. Purified proteins were analyzed by SDS-PAGE and Coomassie Brilliant Blue staining.

\section{GST pulldown experiments}

In vitro binding experiments were performed with recombinant GST fusion proteins purified from E.coli and immobilized on glutathione-Sepharose 4B beads (Life Technologies \#17-075601). Purification of GST fusion proteins was performed as described (Ebnet et al., 2000). For protein interaction experiments the putative partner protein (prey) was expressed in HEK293T cells by transient transfection. Cells were lysed as described for immunoprecipitations. Lysates were incubated with $3 \mu \mathrm{g}$ of immobilized GST fusion protein for $2 \mathrm{~h}$ at $4^{\circ} \mathrm{C}$ under constant agitation. After 5 washing steps in lysis buffer, bound proteins were eluted by boiling for 5 min 
in SDS sample buffer, subjected to SDS-PAGE and analyzed by western blotting using preyspecific antibodies.

\section{In vitro phosphorylation and dephosphorylation assays}

Phosphorylation studies were performed essentially as described before (Iden et al, 2012). Briefly, GST fusion proteins were coupled to glutathione sepharose (GE Healthcare, Freiburg, Germany) using 1x buffer B (10 mM HEPES-NaOH pH 7.4, $100 \mathrm{mM} \mathrm{KCl,} 1 \mathrm{mM} \mathrm{MgCl}, 0.1 \%$ Triton X-100) and subjected to in vitro-kinase reactions with recombinant PKCa. Assays were carried out with $10 \mathrm{ng}$ recombinant enzyme and $5 \mu \mathrm{Ci} \mathrm{y}-\left[{ }^{32} \mathrm{P}\right]$-labeled ATP in PKC $\alpha$ kinase buffer (20 mM HEPES pH 7.4, $700 \mu \mathrm{M} \mathrm{CaCl}_{2}, 25 \mathrm{mM} \mathrm{MgCl}_{2}, 0.25 \mathrm{mM}$ cold ATP) for 30 min at $30^{\circ} \mathrm{C}$ in the presence of $1: 10$ diluted PKC lipid activator (10x lipid activator: $0.5 \mathrm{mg} / \mathrm{ml}$ phosphatidylserine, $50 \mu \mathrm{g} / \mathrm{ml}$ 1-stearoyl-2-linoleoyl-sn-glycerol, 50 $\mu \mathrm{g} / \mathrm{ml}$ 1-oleoyl-2-acetyl-snglycerol, 0,15 \% Triton X-100, $1 \mathrm{mM}$ DTT, $2 \mathrm{mM} \mathrm{CaCl}_{2}, 20 \mathrm{mM}$ MOPS, pH 7.2). For in vitro dephosphorylation assays, the phosphorylated GST fusion proteins were washed in buffer B, then incubated for 30 min at RT with $2 \mathrm{U} /$ sample recombinant PP1 $\alpha$ (Eurofins) in PP1 $\alpha$ reaction buffer (57 mM HEPES pH 7.2, 10 mM MnCl $2,0.167 \mathrm{mM} \mathrm{DTT,} 0.83 \%$ (v/v) glycerol, $0.0167 \%$ BSA, $0.002 \%$ Brij 35). The GST fusion proteins were washed and subsequently eluted from the beads by boiling in SDS sample buffer. Eluted proteins were separated by SDS-PAGE and analyzed by autoradiography.

\section{Cell aggregation assays}

Cell aggregation assays were performed essentially as described previously (Brinkmann et al, 2016). Briefly, HEK293T cells were transiently transfected with expression vectors encoding JAM-A, CAR or TMIGD1. After $24 \mathrm{~h}$ cells were harvested, resuspend in HBSS and then adjusted to $5 \times 10^{5}$ cells $/ \mathrm{ml}$. $3 \mathrm{ml}$ of cell suspension were added to a $30-\mathrm{mm}$ BSA-coated 6well tissue culture dishes and incubated on a horizontal shaker at $40 \mathrm{rpm}$ for $45 \mathrm{~min}$ at $37^{\circ} \mathrm{C}$. Cells were fixed by addition of $500 \mu \mathrm{l} 25 \%$ glutaraldehyde and incubation on ice for $30 \mathrm{~min}$. Fixed cells were analyzed by microscopic analysis at 10x magnification. Five to ten pictures 
were analyzed for each condition. The number of particles was counted using ImageJ software, particles larger than $256 \mu \mathrm{m}^{2}$ were considered as aggregates. Data are presented as means \pm standard error (SEM) from five independent experiments. $P$-values: ${ }^{*} P<0.05,{ }^{* * *} P<0.001$ and ${ }^{* * * *} \mathrm{P}<0.0001$

\section{Bead aggregation assays}

Bead aggregation assays were performed essentially as described (Emond et al, 2011). Briefly, equal amounts of Fc-fusion proteins consisting of the extracellular domains of TMIGD1 (TMIGD1-Fc), JAM-B (JAM-B-Fc) or JAM-C (JAM-C-Fc) fused C-terminally to the Fc-part of human IgG were coupled to red fluorescent, protein A-coated beads (BNF-StarchredF/ProteinA, 100 nm, micromod Partikeltechnologie GmbH, Rostock, Germany, \#64-20102). Beads were washed three times in aggregation buffer (50 mM Tris- $\mathrm{HCl}(\mathrm{pH} 7.4), 100 \mathrm{mM}$ $\mathrm{NaCl}, 10 \mathrm{mM} \mathrm{KCl}, 0.2 \% \mathrm{BSA}$ ) to remove unbound Fc-fusion proteins. After trituration by vigorous pipetting and vortexing, beads were resuspended in aggregation buffer transferred to 15-ml conical tubes and incubated for $30 \mathrm{~min}$ at $\mathrm{RT}{ }^{\circ} \mathrm{C}$ under constant shaking (180 rpm) Beads were carefully transferred to microscopic slides. Fluorescent images were collected on a microscope (LSM 800) with a 10x Plan-Apochromat x 63/1.4 oil objective. Aggregate formation was analyzed by measuring the total area of fluorescence within a given field of view using ImageJ software. At least 25 fields of view were analyzed per experiment (three independent experiments). Statistical analysis was performed using Ordinary one-way ANOVA with Dunnett's multiple comparison, data are presented as means \pm standard error (SEM). P. value: ${ }^{* * *} \mathrm{P}<0.0001$.

\section{Immunofluorescence microscopy}

For immunofluorescence microscopy, cells were grown on collagen-coated glass slides or collagen-coated transwell polycarbonate membrane filters $(0.4 \mu \mathrm{m}$ pore size, Corning, Amsterdam, The Netherlands). Cells were washed with PBS and fixed with 4\% paraformaldehyde (PFA, SA) for $7 \mathrm{~min}$. To detect intracellular proteins, PFA-fixed cells were 
incubated with PBS containing $0.2 \%$ Triton X-100 for 15 min. Cells were washed with $100 \mathrm{mM}$ glycine in PBS, blocked for $1 \mathrm{~h}$ in blocking buffer (PBS, 10\% FCS, 0.2\% Triton X-100, 0.05\% Tween-20, 0.02\% BSA) and then incubated with primary antibodies in blocking buffer for $1 \mathrm{~h}$ at room temperature $(\mathrm{RT})$ or overnight at $4^{\circ} \mathrm{C}$. After incubation, cells were washed three times with PBS and incubated with fluorochrome (AlexaFluor488, AlexaFluor594 and AlexaFluor647)-conjugated, highly cross-adsorbed secondary antibodies (Invitrogen) for 2 hrs at RT protected from light. F-Actin was stained using phalloidin-conjugates (TRITC and cytoPainter iFluor-647, DNA was stained with 4,6-diamidino-2-phenylindole (DAPI, SigmaAldrich). Samples were washed three times with PBS and mounted in fluorescence mounting medium (Mowiol 4-88, Sigma Aldrich). Immunofluorescence microscopy was performed using the confocal microscopes LSM 780 and LSM 800 Airyscan (both from Carl Zeiss, Jena, Germany) equipped with the objectives Plan-Apochromat x 63/1.4 oil differential interference contrast (Carl Zeiss). Image processing and quantification was performed using ImageJ, Zen 2 (Blue Edition, Carl Zeiss) and Imaris (Bitplane, Version 9.1.2) software.

For quantification of TMIGD1 recruitment by EBP50 and/or E3KARP to polarized caps of LS174T-W4 cells, a total number of at least 92 and a maximum of 142 cells per condition (3 independent experiments) was analyzed. Only cells containing a polarized brush border (polarized ezrin or Eps8 signals after doxycycline-treatment) and successfully transfected with TMIGD1 were included in the analysis. Statistical analysis was performed using unpaired student's $t$ test, data is plotted as means \pm standard deviation (SD). P-values: ${ }^{*} \mathrm{P}<0.05$, $\star * * * P<0.001$.

\section{FRAP experiments}

For FRAP experiments, JEG-3 cells grown on collagen-coated glass bottom slides (Ibidi \#80827) were analyzed by time-lapse microscopy on a confocal-laser scanning microscope (Carl Zeiss, Jena Germany, LSM 800 Airyscan) in a $37^{\circ} \mathrm{C}$ chamber. FRAP measurements and quantifications were performed essentially as described before (Kondadi et al, 2020). A square region of $3.7 \times 3.7 \mu$ m was bleached using $100 \%$ laser power of URGB Diodes at $488 \mathrm{~nm}$ 
(Diode laser $488 \mathrm{~nm}, 10 \mathrm{~mW}$ ). To monitor fluorescence recovery over time 5 pre-bleach images and 145 - 195 post-bleach images of a given region of interest (ROI) were acquired. For FRAP quantification three ROls were defined: $\mathrm{ROI}_{1}$ (region with no microvilli, used to perform background subtraction), $\mathrm{ROI}_{2}$ (region with microvilli where photobleaching was performed), $\mathrm{ROI}_{3}$ (region with microvilli where photobleaching was not performed, used to obtain the correction factor for the amount of bleaching during monitoring). Photobleach correction was performed by dividing the background-subtracted intensity values obtained at $\mathrm{ROI}_{2}\left(\mathrm{ROI}_{2}-\right.$ $\left.\mathrm{ROI}_{1}\right)$ by those obtained at $\mathrm{ROI}_{3}\left(\mathrm{ROI}_{3}-\mathrm{ROI}_{1}\right)$. Normalization of ROls was performed with ImageJ software (Fiji) using the FRAP Norm plugin (https://imagejdocu.tudor.lu/doku.php?id=plugin:analysis:frap_normalization:start.) which uses the normalization method outlined in (Phair et al, 2004). Normalized FRAP recovery values were fitted using GraphPad Prism 6 by nonlinear regression two phase association model. FRAP graphs represent fitted curves with means \pm standard deviation (SD). First and second association $\mathrm{t}_{1 / 2}$ recovery values were obtained when the curves were fitted by nonlinear regression two-phase association model. For each condition a total number of 50 to 143 cells obtained from 3 independent experiments were analyzed. Statistical analysis of differences between recovery curves of cells without and cells with TMIGD1 expression was performed using Two-way Repeated Measurements ANOVA. ${ }^{*} \mathrm{P}<0.05$, ${ }^{* * *} \mathrm{P}<0.001$.

\section{Intestinal organoids}

Organoids derived from intestinal crypts were generated essentially as described (Mosa et al, 2018). Briefly, after mechanical removal of villi, intestinal tissue was cut into small tissue pieces $(2-4 \mathrm{~cm})$ and incubated in PBS/2mM EDTA for $30 \mathrm{~min}$ on ice. The material was passed through a $70 \mu \mathrm{m}$ strainer, followed by centrifugation $\left(140 \mathrm{xg}, 5 \mathrm{~min}, 4^{\circ} \mathrm{C}\right)$. The pellet was resupended in AD-DF+++ medium (Advanced DMEM/F12 (Gibco, \#12634-010), 2 mM L-Glu (Lonza, \#17-602E, 100 U/ml Pen/Strep (Lonza, \#17-602E), 10 mM HEPES (Sigma, \#H0887) and resupended in ice-cold matrigel. $50-\mu$ l aliquots of the matrigel suspension were transferred to pre-warmed 24-well plates, allowed to solidify, then covered with complete growth medium 
(80\% AD-DF+++, $10 \%$ Rspondl conditioned medium, $10 \%$ Noggin conditioned medium, 0.5 $\mu \mathrm{g} / \mathrm{ml}$ mEGF (Gibco, \#PMG8043), $0.1 \mathrm{mg} / \mathrm{ml}$ Primocin (InvivoGen, \#ant-pm-0.5), 1X B-27 supplement (Gibco, \#175044), 1.25 mM N-Acetyl-L-Cysteine (Sigma, \#A9165-5G)). Organoids were cultured for 7 days with medium changes every 2 to 3 days. For continuous culture, organoids were mechanically disrupted by vigorous pipetting to generate single crypts, then resuspended in matrigel and transferred to new tissue culture dishes as described above. Organoids were maintained as a polyclonal pool.

For immunofluorescence staining crypts were grown for 3 days in single matrigel droplets on $15 \mu$-slide 8 well glass bottom ibidi slides (\#80827, Ibidi). Prior to fixation the matrigel was dissolved by incubation on ice in cell-recovery solution (\#354253, Corning) for approx. $1 \mathrm{~h}$. Organoids were fixed in 4\% PFA/PBS for $1 \mathrm{~h}$ at room temperature, washed with PBS and incubated in quenching solution (130 mM NaCl, $100 \mathrm{mM}$ glycine, $7 \mathrm{mM} \mathrm{Na}_{2} \mathrm{HPO}_{4}$ and $3.5 \mathrm{mM}$ $\mathrm{NaH}_{2} \mathrm{PO}_{4} ; 30$ min). After permeabilization (0.5\% Triton X-100 in PBS for $\left.1 \mathrm{~h}\right)$ and blocking (PBS, $0.02 \%$ BSA, 0.05\% Tween20, 0.05\% Triton X-100, 5\% goat serum, 5\% donkey serum, at least $2 \mathrm{~h}$ ) organoids were incubated with primary antibodies in blocking buffer at $4^{\circ} \mathrm{C}$ overnight followed by incubation with fluorophore-conjugated secondary antibodies for $2 \mathrm{~h}$ at RT. Organoids were imaged with a Zeiss LSM800 using the Airyscan mode and a $63 \times$ oil immersion objective (numeric aperture, 1.4).

\section{Electron microscopy}

Electron microscopy was performed with Caco-2 ${ }_{\mathrm{BBe}}$ cells grown on polycarbonate filters for 22 $d$ to induce differentiation. For pre-embedding immunogold labelling, cells were fixed with $2 \%$ paraformaldehyde (Polysciences, Warrington PA, USA) in PBS (pH7.4). Cells were incubated with rabbit anti-TMIGD1 pAb, followed by incubation with 15-nm gold particle-conjugated protein A (Department of Cell Biology, University Medical Center, Utrecht, The Netherlands). After fixation with $2 \%$ glutaraledhyde (Polysciences) in PBS (pH7.4), samples were counterstained with osmiumtetroxide (Polysciences) and embedded in epoxy resin (Agar Scientific, Essex, UK). 60-nm ultrathin sections were generated using an ultramicrotome 
(Leica-UC6 ultramicrotome, Vienna, Austria). For immunogold labelling of ultrathin cryosections, cells were fixed with $2 \%$ paraformaldehyde, $0.2 \%$ glutaraldehyde in PBS $(\mathrm{pH}$ 7.4) and processed for immuno-labelling electron microscopy according to the method of Tokuyasu (Tokuyasu, 1980). 60-nm ultrathin sections (Leica-UC6 ultramicrotome) were labelled with rabbit anti-TMIGD1 pAb as described above. All samples were analyzed at $80 \mathrm{kV}$ on a FEI-Tecnai 12 electron microscope (FEI, Eindhoven, The Netherlands). Selected areas were documented with Veleta 4k CCD camera (EMSIS GmbH, Münster, Germany). Analysis of TMIGD1 immunogold-labelling was performed on three independent sections and a total of 340 individual cells. Of these cells, 23 (6.8\%) were positive for gold particles.

\section{Acknowledgements}

We gratefully acknowledge the help of Drs Lucas J. M. Bruurs, Johan L. Bos and Hans Clevers (Oncode Institute, University Medical Center Utrecht, Utrecht, The Netherlands) for providing us LS174T:W4 cells. We thank Dr. H.-J. Kreienkamp (Institute for Human Genetics, University Medical Center Hamburg-Eppendorf, Hamburg, Germany) for providing us with the NHERF1GFP plasmid vector. We also thank Dr. Thomas Weide (Department of Internal Medicine D, Division of Molecular Nephrology, University Hospital Münster, Germany) for providing us with the plnducer21-Puro plasmid vector.

\section{Author contributions}

C.H. and K.E. designed and conceived the study. C.H., E.-M.T., B.E.M., D.P., S.L., L.G., F.B. and M.G.-E. performed experiments. C.H., L.G., E.W., T.Z., M.A.S., V.G. and K.E. analyzed the data. C.H. and K.E. wrote the manuscript.

\section{Abbreviations}

AA, amino acid, E3KARP, NHE3 kinase A regulatory protein; EBP50, ERM-binding phosphoprotein of $50 \mathrm{kDa}$; FRAP, fluorescence recovery after photobleaching; IF, 
immunofluorescence; JAM-A, Junctional Adhesion Molecule-A; NHERF, $\mathrm{Na}^{+} / \mathrm{H}^{+}$exchange regulatory cofactor; PBM, PDZ domain-binding motif; PDZ, Postsynaptic density 95 - Discs Large - Zonula occludens-1; TMIGD1, Transmembrane and immunoglobulin domaincontaining protein 1

\section{Competing interests}

The authors declare that they have no conflict of interest.

\section{Funding resources}

This work was supported by grants from the Deutsche Forschungsgemeinschaft (EB 160/5-1; EB 160/8-1; EXC 1003- CiMIC) and from the Medical Faculty of the University of Münster (IZKF Eb2/020/14).

\section{References}

Arafa E, Bondzie PA, Rezazadeh K, Meyer RD, Hartsough E, Henderson JM, Schwartz JH, Chitalia V, Rahimi N (2015) TMIGD1 is a novel adhesion molecule that protects epithelial cells from oxidative cell injury. The American journal of pathology 185: 2757-2767

Baas AF, Kuipers J, van der Wel NN, Batlle E, Koerten HK, Peters PJ, Clevers HC (2004) Complete polarization of single intestinal epithelial cells upon activation of LKB1 by STRAD. Cell 116: 457-466

Bhattacharya S, Dai Z, Li J, Baxter S, Callaway DJ, Cowburn D, Bu Z (2010) A conformational switch in the scaffolding protein NHERF1 controls autoinhibition and complex formation. The Journal of biological chemistry 285: 9981-9994

Bhattacharya S, Stanley CB, Heller WT, Friedman PA, Bu Z (2019) Dynamic structure of the full-length scaffolding protein NHERF1 influences signaling complex assembly. The Journal of biological chemistry 294: 11297-11310

Bretscher A (1983) Purification of an 80,000-dalton protein that is a component of the isolated microvillus cytoskeleton, and its localization in nonmuscle cells. The Journal of cell biology 97: 425-432

Brinkmann BF, Steinbacher T, Hartmann C, Kummer D, Pajonczyk D, Mirzapourshafiyi F, Nakayama M, Weide T, Gerke V, Ebnet K (2016) VE-cadherin interacts with cell polarity protein Pals1 to regulate vascular lumen formation. Molecular biology of the cell 27: 2811-2821

Canals D, Roddy P, Hannun YA (2012) Protein phosphatase 1alpha mediates ceramide-induced ERM protein dephosphorylation: a novel mechanism independent of phosphatidylinositol 4, 5-biphosphate (PIP2) and myosin/ERM phosphatase. The Journal of biological chemistry 287: 10145-10155 
Cattaneo E, Laczko E, Buffoli F, Zorzi F, Bianco MA, Menigatti M, Bartosova Z, Haider R, Helmchen B, Sabates-Bellver J et al (2011) Preinvasive colorectal lesion transcriptomes correlate with endoscopic morphology (polypoid vs. nonpolypoid). EMBO molecular medicine 3: 334-347

Cheng H, Li J, Fazlieva R, Dai Z, Bu Z, Roder H (2009) Autoinhibitory interactions between the PDZ2 and C-terminal domains in the scaffolding protein NHERF1. Structure 17: 660-669

Claessens MM, Bathe M, Frey E, Bausch AR (2006) Actin-binding proteins sensitively mediate F-actin bundle stiffness. Nat Mater 5: 748-753

Coscoy S, Waharte F, Gautreau A, Martin M, Louvard D, Mangeat P, Arpin M, Amblard F (2002) Molecular analysis of microscopic ezrin dynamics by two-photon FRAP. P Natl Acad Sci USA 99: 12813-12818

Crawley SW, Mooseker MS, Tyska MJ (2014a) Shaping the intestinal brush border. The Journal of cell biology 207: 441-451

Crawley SW, Shifrin DA, Jr., Grega-Larson NE, McConnell RE, Benesh AE, Mao S, Zheng Y, Zheng QY, Nam KT, Millis BA et al (2014b) Intestinal brush border assembly driven by protocadherin-based intermicrovillar adhesion. Cell 157: 433-446

Crawley SW, Weck ML, Grega-Larson NE, Shifrin DA, Jr., Tyska MJ (2016) ANKS4B Is Essential for Intermicrovillar Adhesion Complex Formation. Developmental cell 36: 190-200

De La Cena KOC, Xi-Yeen Ho R, Amraei R, Woolf N, Tashjian JY, Zhao Q, Richards S, Walker J, Huang J, Chitalia V et al (2020) Transmembrane and Immunoglobulin Domain Containing 1, a Putative Tumor Suppressor, Induces G2/M Cell Cycle Checkpoint Arrest in Colon Cancer Cells. The American journal of pathology

Delacour D, Salomon J, Robine S, Louvard D (2016) Plasticity of the brush border - the yin and yang of intestinal homeostasis. Nat Rev Gastroenterol Hepatol 13: 161-174

Doyle DA, Lee A, Lewis J, Kim E, Sheng M, MacKinnon R (1996) Crystal structures of a complexed and peptide-free membrane protein- binding domain: molecular basis of peptide recognition by PDZ. Cell 85: 1067-1076

Ebnet K, Aurrand-Lions M, Kuhn A, Kiefer F, Butz S, Zander K, Meyer Zu Brickwedde MK, Suzuki A, Imhof BA, Vestweber D (2003) The junctional adhesion molecule (JAM) family members JAM-2 and JAM-3 associate with the cell polarity protein PAR-3: A possible role for JAMs in endothelial cell polarity. J Cell Sci 116: 3879-3891

Ebnet K, Schulz CU, Meyer Zu Brickwedde MK, Pendl GG, Vestweber D (2000) Junctional adhesion molecule interacts with the PDZ domain-containing proteins AF-6 and ZO-1. The Journal of biological chemistry 275: 27979-27988

Emond MR, Biswas S, Blevins CJ, Jontes JD (2011) A complex of Protocadherin-19 and N-cadherin mediates a novel mechanism of cell adhesion. The Journal of cell biology 195: 1115-1121

Evan GI, Lewis GK, Ramsay G, Bishop JM (1985) Isolation of monoclonal antibodies specific for human C-myc proto-oncogene product. Molecular and cellular biology 5: 3610-3616

Garbett D, Bretscher A (2012) PDZ interactions regulate rapid turnover of the scaffolding protein EBP50 in microvilli. The Journal of cell biology 198: 195-203

Garbett D, LaLonde DP, Bretscher A (2010) The scaffolding protein EBP50 regulates microvillar assembly in a phosphorylation-dependent manner. The Journal of cell biology 191: 397-413

Garbett D, Sauvanet C, Viswanatha R, Bretscher A (2013) The tails of apical scaffolding proteins EBP50 and E3KARP regulate their localization and dynamics. Molecular biology of the cell 24: 3381-3392

Gardoni F, Polli F, Cattabeni F, Di Luca M (2006) Calcium-calmodulin-dependent protein kinase II phosphorylation modulates PSD-95 binding to NMDA receptors. Eur J Neurosci 24: 2694-2704 
Gary R, Bretscher A (1995) Ezrin self-association involves binding of an N-terminal domain to a normally masked $\mathrm{C}$-terminal domain that includes the F-actin binding site. Molecular biology of the cell 6 : 1061-1075

Gorelik J, Shevchuk AI, Frolenkov GI, Diakonov IA, Lab MJ, Kros CJ, Richardson GP, Vodyanoy I, Edwards CR, Klenerman D et al (2003) Dynamic assembly of surface structures in living cells. $P$ Natl Acad Sci USA 100: 5819-5822

Hall RA, Spurney RF, Premont RT, Rahman N, Blitzer JT, Pitcher JA, Lefkowitz RJ (1999) G proteincoupled receptor kinase $6 \mathrm{~A}$ phosphorylates the $\mathrm{Na}(+) / \mathrm{H}(+)$ exchanger regulatory factor via a PDZ domain-mediated interaction. The Journal of biological chemistry 274: 24328-24334

Hanono A, Garbett D, Reczek D, Chambers DN, Bretscher A (2006) EPI64 regulates microvillar subdomains and structure. The Journal of cell biology 175: 803-813

Hartmann C, Schwietzer YA, Kummer D, Kirschnick N, Hoppe E, Thuring EM, Glaesner-Ebnet M, Brinkmann F, Gerke V, Reuter S et al (2020) The mitochondrial outer membrane protein SYNJ2BP interacts with the cell adhesion molecule TMIGD1 and can recruit it to mitochondria. BMC Mol Cell Biol 21: 30

He J, Lau AG, Yaffe MB, Hall RA (2001) Phosphorylation and cell cycle-dependent regulation of $\mathrm{Na}+/ \mathrm{H}+$ exchanger regulatory factor-1 by Cdc2 kinase. The Journal of biological chemistry 276: 41559-41565

Hollenberg SM, Sternglanz R, Cheng PF, Weintraub H (1995) Identification of a new family of tissuespecific basic helix-loop- helix proteins with a two-hybrid system. Mol Cell Biol 15: 3813-3822

Honig B, Shapiro L (2020) Adhesion Protein Structure, Molecular Affinities, and Principles of Cell-Cell Recognition. Cell 181: 520-535

Iden S, Misselwitz S, Peddibhotla SS, Tuncay H, Rehder D, Gerke V, Robenek H, Suzuki A, Ebnet K (2012) aPKC phosphorylates JAM-A at Ser285 to promote cell contact maturation and tight junction formation. The Journal of cell biology 196: 623-639

Keegan K, Cooper JA (1996) Use of the two hybrid system to detect the association of the proteintyrosine-phosphatase, SHPTP2, with another SH2-containing protein, Grb7. Oncogene 12: 15371544

Klingner C, Cherian AV, Fels J, Diesinger PM, Aufschnaiter R, Maghelli N, Keil T, Beck G, TolicNorrelykke IM, Bathe M et al (2014) Isotropic actomyosin dynamics promote organization of the apical cell cortex in epithelial cells. The Journal of cell biology 207: 107-121

Kondadi AK, Anand R, Hansch S, Urbach J, Zobel T, Wolf DM, Segawa M, Liesa M, Shirihai OS, Weidtkamp-Peters $S$ et al (2020) Cristae undergo continuous cycles of membrane remodelling in a MICOS-dependent manner. EMBO reports 21: e49776

Kremer KN, Dudakovic A, Hess AD, Smith BD, Karp JE, Kaufmann SH, Westendorf JJ, van Wijnen AJ, Hedin KE (2015) Histone Deacetylase Inhibitors Target the Leukemic Microenvironment by Enhancing a Nherf1-Protein Phosphatase 1alpha-TAZ Signaling Pathway in Osteoblasts. The Journal of biological chemistry 290: 29478-29492

LaLonde DP, Garbett D, Bretscher A (2010) A regulated complex of the scaffolding proteins PDZK1 and EBP50 with ezrin contribute to microvillar organization. Molecular biology of the cell 21: 1519-1529

Lee J, Park EJ, Yuki Y, Ahmad S, Mizuguchi K, Ishii KJ, Shimaoka M, Kiyono H (2015) Profiles of microRNA networks in intestinal epithelial cells in a mouse model of colitis. Sci Rep 5: 18174

Li J, Callaway DJ, Bu Z (2009) Ezrin induces long-range interdomain allostery in the scaffolding protein NHERF1. Journal of molecular biology 392: 166-180

Li J, Poulikakos PI, Dai Z, Testa JR, Callaway DJ, Bu Z (2007) Protein kinase C phosphorylation disrupts $\mathrm{Na}+/ \mathrm{H}+$ exchanger regulatory factor 1 autoinhibition and promotes cystic fibrosis transmembrane 
conductance regulator macromolecular assembly. The Journal of biological chemistry 282: 27086 27099

Liu X, Fuentes EJ (2019) Emerging Themes in PDZ Domain Signaling: Structure, Function, and Inhibition. International review of cell and molecular biology 343: 129-218

Loomis PA, Zheng L, Sekerkova G, Changyaleket B, Mugnaini E, Bartles JR (2003) Espin cross-links cause the elongation of microvillus-type parallel actin bundles in vivo. The Journal of cell biology 163: 1045-1055

Matsui T, Yonemura S, Tsukita S (1999) Activation of ERM proteins in vivo by Rho involves phosphatidyl-inositol 4-phosphate 5-kinase and not ROCK kinases. Current biology : CB 9: 12591262

Mauceri D, Gardoni F, Marcello E, Di Luca M (2007) Dual role of CaMKII-dependent SAP97 phosphorylation in mediating trafficking and insertion of NMDA receptor subunit NR2A. Journal of neurochemistry 100: 1032-1046

Meenderink LM, Gaeta IM, Postema MM, Cencer CS, Chinowsky CR, Krystofiak ES, Millis BA, Tyska MJ (2019) Actin Dynamics Drive Microvillar Motility and Clustering during Brush Border Assembly. Developmental cell 50: 545-556 e544

Meyer RD, Zou X, Ali M, Ersoy E, Bondzie PA, Lavaei M, Alexandrov I, Henderson J, Rahimi N (2018) TMIGD1 acts as a tumor suppressor through regulation of p21Cip1/p27Kip1 in renal cancer. Oncotarget 9: 9672-9684

Mojica W, Hawthorn L (2010) Normal colon epithelium: a dataset for the analysis of gene expression and alternative splicing events in colon disease. BMC Genomics 11: 5

Mooseker MS, Pollard TD, Wharton KA (1982) Nucleated polymerization of actin from the membraneassociated ends of microvillar filaments in the intestinal brush border. The Journal of cell biology 95: 223-233

Morales FC, Takahashi Y, Kreimann EL, Georgescu MM (2004) Ezrin-radixin-moesin (ERM)-binding phosphoprotein 50 organizes ERM proteins at the apical membrane of polarized epithelia. $P$ Natl Acad Sci USA 101: 17705-17710

Morales FC, Takahashi Y, Momin S, Adams H, Chen X, Georgescu MM (2007) NHERF1/EBP50 headto-tail intramolecular interaction masks association with PDZ domain ligands. Molecular and cellular biology 27: 2527-2537

Mosa MH, Nicolle O, Maschalidi S, Sepulveda FE, Bidaud-Meynard A, Menche C, Michels BE, Michaux G, de Saint Basile G, Farin HF (2018) Dynamic Formation of Microvillus Inclusions During Enterocyte Differentiation in Munc18-2-Deficient Intestinal Organoids. Cell Mol Gastroenterol Hepatol 6: 477493 e471

Murakami H, Masui H (1980) Hormonal control of human colon carcinoma cell growth in serum-free medium. P Natl Acad Sci USA 77: 3464-3468

Pedersen SW, Albertsen L, Moran GE, Levesque B, Pedersen SB, Bartels L, Wapenaar H, Ye F, Zhang M, Bowen ME et al (2017) Site-Specific Phosphorylation of PSD-95 PDZ Domains Reveals FineTuned Regulation of Protein-Protein Interactions. ACS Chem Biol 12: 2313-2323

Pelaseyed T, Bretscher A (2018) Regulation of actin-based apical structures on epithelial cells. Journal of cell science 131

Peterson MD, Mooseker MS (1992) Characterization of the enterocyte-like brush border cytoskeleton of the C2BBe clones of the human intestinal cell line, Caco-2. Journal of cell science 102 ( $\mathrm{Pt} 3$ ): 581600 
Phair RD, Gorski SA, Misteli T (2004) Measurement of dynamic protein binding to chromatin in vivo, using photobleaching microscopy. Methods in enzymology 375: 393-414

Pinette JA, Mao S, Millis BA, Krystofiak ES, Faust JJ, Tyska MJ (2019) Brush border protocadherin CDHR2 promotes the elongation and maximized packing of microvilli in vivo. Molecular biology of the cell 30: 108-118

Raghuram V, Hormuth H, Foskett JK (2003) A kinase-regulated mechanism controls CFTR channel gating by disrupting bivalent PDZ domain interactions. P Natl Acad Sci USA 100: 9620-9625

Reczek D, Berryman M, Bretscher A (1997) Identification of EBP50: A PDZ-containing phosphoprotein that associates with members of the ezrin-radixin-moesin family. The Journal of cell biology 139: 169-179

Reczek D, Bretscher A (1998) The carboxyl-terminal region of EBP50 binds to a site in the aminoterminal domain of ezrin that is masked in the dormant molecule. The Journal of biological chemistry 273: $18452-18458$

Rehder D, Iden S, Nasdala I, Wegener J, Brickwedde MK, Vestweber D, Ebnet K (2006) Junctional adhesion molecule-A participates in the formation of apico-basal polarity through different domains. Exp Cell Res 312: 3389-3403

Roberts DL, O'Dwyer ST, Stern PL, Renehan AG (2015) Global gene expression in pseudomyxoma peritonei, with parallel development of two immortalized cell lines. Oncotarget

Sauvanet C, Garbett D, Bretscher A (2015a) The function and dynamics of the apical scaffolding protein E3KARP are regulated by cell-cycle phosphorylation. Molecular biology of the cell 26: 3615-3627

Sauvanet C, Wayt J, Pelaseyed T, Bretscher A (2015b) Structure, regulation, and functional diversity of microvilli on the apical domain of epithelial cells. Annual review of cell and developmental biology 31: 593-621

Schiestl RH, Gietz RD (1989) High efficiency transformation of intact yeast cells using single stranded nucleic acids as a carrier. Curr Genet 16: 339-346

Short DB, Trotter KW, Reczek D, Kreda SM, Bretscher A, Boucher RC, Stutts MJ, Milgram SL (1998) An apical PDZ protein anchors the cystic fibrosis transmembrane conductance regulator to the cytoskeleton. The Journal of biological chemistry 273: 19797-19801

Stidwill RP, Wysolmerski T, Burgess DR (1984) The brush border cytoskeleton is not static: in vivo turnover of proteins. The Journal of cell biology 98: 641-645

Takahashi Y, Morales FC, Kreimann EL, Georgescu MM (2006) PTEN tumor suppressor associates with NHERF proteins to attenuate PDGF receptor signaling. The EMBO journal 25: 910-920

Terawaki S, Maesaki R, Hakoshima T (2006) Structural basis for NHERF recognition by ERM proteins. Structure 14: 777-789

Tokuyasu KT (1980) Immunochemistry on ultrathin frozen sections. The Histochemical journal 12: 381403

Tuncay H, Brinkmann BF, Steinbacher T, Schurmann A, Gerke V, Iden S, Ebnet K (2015) JAM-A regulates cortical dynein localization through $\mathrm{Cdc} 42$ to control planar spindle orientation during mitosis. Nature communications 6: 8128

Tyska MJ, Mooseker MS (2002) MYO1A (brush border myosin I) dynamics in the brush border of LLCPK1-CL4 cells. Biophysical journal 82: 1869-1883

Vaquero J, Nguyen Ho-Bouldoires TH, Claperon A, Fouassier L (2017) Role of the PDZ-scaffold protein NHERF1/EBP50 in cancer biology: from signaling regulation to clinical relevance. Oncogene 36: 3067-3079 
Viswanatha R, Bretscher A, Garbett D (2014) Dynamics of ezrin and EBP50 in regulating microvilli on the apical aspect of epithelial cells. Biochem Soc Trans 42: 189-194

Viswanatha R, Ohouo PY, Smolka MB, Bretscher A (2012) Local phosphocycling mediated by LOK/SLK restricts ezrin function to the apical aspect of epithelial cells. The Journal of cell biology 199: 969984

Viswanatha R, Wayt J, Ohouo PY, Smolka MB, Bretscher A (2013) Interactome analysis reveals ezrin can adopt multiple conformational states. The Journal of biological chemistry 288: 35437-35451

Weck ML, Crawley SW, Stone CR, Tyska MJ (2016) Myosin-7b Promotes Distal Tip Localization of the Intermicrovillar Adhesion Complex. Current biology : CB 26: 2717-2728

Weinman EJ, Steplock D, Wang Y, Shenolikar S (1995) Characterization of a protein cofactor that mediates protein kinase A regulation of the renal brush border membrane $\mathrm{Na}(+)-\mathrm{H}+$ exchanger. The Journal of clinical investigation 95: 2143-2149

Zabana Y, Loren V, Domenech E, Aterido A, Garcia-Jaraquemada A, Julia A, Vicario M, Pedrosa E, Ferreiro M, Troya J et al (2020) Transcriptomic identification of TMIGD1 and its relationship with the ileal epithelial cell differentiation in Crohn's disease. American journal of physiology 319: G109-G120

Zhang Q, Xiao K, Paredes JM, Mamonova T, Sneddon WB, Liu H, Wang D, Li S, McGarvey JC, Uehling $\mathrm{D}$ et al (2019) Parathyroid hormone initiates dynamic NHERF1 phosphorylation cycling and conformational changes that regulate NPT2A-dependent phosphate transport. The Journal of biological chemistry 294: 4546-4571

Zwaenepoel I, Naba A, Da Cunha MM, Del Maestro L, Formstecher E, Louvard D, Arpin M (2012) Ezrin regulates microvillus morphogenesis by promoting distinct activities of Eps8 proteins. Molecular biology of the cell 23: 1080-1094 


\section{Figure legends}

Figure 1: TMIGD1 is a novel component of microvilli. (A) IF staining of TMIGD1 in differentiated Caco-2 $2_{\text {Bbe1 }}$ cells (left panel) and T84 cells (right panel). Scale bars: $5 \mu \mathrm{m}$. (B) IF stainings of TMIGD1 with microvilli markers villin, ezrin and Eps8. Scale bars: $5 \mu \mathrm{m}$. (C)

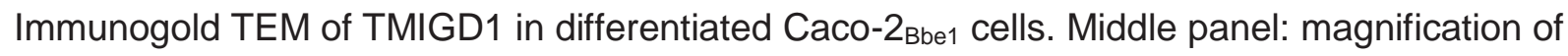
the framed area in the left panel. Right panel: Relative position of the gold particles along the microvillar axis. Total number of TMIGD1-positive cells: 23 (6.8\% of analyzed cells $(n=340)$. Distribution of gold particles: distal tip: 3; basal region: 20. Scale bar: $100 \mathrm{~nm}$. (D) IF stainings of TMIGD1 and villin in LS174T-W4 cells without and with doxycycline (Dox) treatment. Scale bars: $5 \mu \mathrm{m}$. (E) IF staining of ectopic TMIGD1 and either ezrin or Eps8 in unpolarized (-Dox) and polarized (+Dox) LS174T-W4 cells. Scale bars: $5 \mu \mathrm{m}$. (F) IF staining of ectopic TMIGD1 and Eps8 in polarized LS174T-W4 cells. Note the localization of TMIGD1 at the subapical region of the brush border and its absence from microvillar distal tips marked by Eps8. Scale bar: $5 \mu \mathrm{m}$. (G) IF staining of TMIGD1 and villin in murine intestinal organoids. Scale bars: Phase contrast image: $20 \mu \mathrm{m}$; IF stainings: $10 \mu \mathrm{m}$.

Figure 2: TMIGD1 directly interacts with microvillar scaffolding protein E3KARP. (A) Schematic organization of E3KARP. The region isolated as a cDNA clone from a Y2H library interacting with TMIGD1 is depicted in red. (B) GST pulldown experiment using the cytoplasmic tails of TMIGD1 (GST-T1, GST-T1/A5), JAM-A (GST-JAM-A), JAM-B (GST-JAM-B) or JAM-C (GST-JAM-C) fused to GST and in vitro translated E3KARP/PDZ1-2. (C) GST-pulldown experiment using GST fusion proteins described in panel B and lysates from HEK293T cells transfected with E3KARP/WT or E3KARP mutants with inactivated PDZ domain 1 (E3KARP/P1M) or PDZ domain 2 (E3KARP/P2M). (D) ColP experiment from HEK293T cells transfected with E3KARP and TMIGD1 deletion constructs (left panel) or transfected with TMIGD1 and E3KARP PDZ domain mutant constructs (right panel). 
Figure 3: TMIGD1 directly interacts with microvillar scaffolding protein EBP50 in an ezrin-regulated manner. (A) CoIP experiment from HEK293T cells transfected with EBP50 and TMIGD1 constructs (TMIGD1/NT, TMIGD1/A5, left panel), or transfected with TMIGD1 and EBP50 PDZ domain mutant constructs (PDZ 1 mutant (EBP50/P1M), PDZ 2 mutant (EBP50/P2M) (right panel). (B) GST pulldown with GST-TMIGD1 cytoplasmic tail fusion proteins (GST-T1, GST-T1/A5) and in vitro translated EBP50 in the presence of recombinant wildtype ezrin (left panel) or recombinant ezrin/T567D (right panel). (C) GST pulldown with GST-TMIGD1 cytoplasmic tail fusion proteins (GST-T1) and in vitro translated EBP50 PDZ domain mutant constructs (EBP50/P1M, EBP50/P2M). (D) Schematic depicting the interaction between TMIGD1 and EBP50 and its regulation by active ezrin.

Figure 4: TMIGD1 is recruited to the brush border by EBP50 and E3KARP. (A) IF staining of transfected TMIGD1/WT (left panel) and TMIGD1/ 5 (right panel) in unpolarized (-Dox) and polarized (+Dox) LS174T-W4 cells. Scale bars: $5 \mu \mathrm{m}$. (B) Left panel: Representative IF images showing the localization of TMIGD1 at polarized brush borders in EBP50 KD, E3KARP KD and EBP50/E3KARP double KD (E50/E3K dKD) LS174T-W4 cells. Scale bars: 5 um. Right panel: Quantitative analysis of cells with TMIGD1 localization at polarized brush borders. Quantification was performed with unpaired Student's t-test. Data is presented as mean values

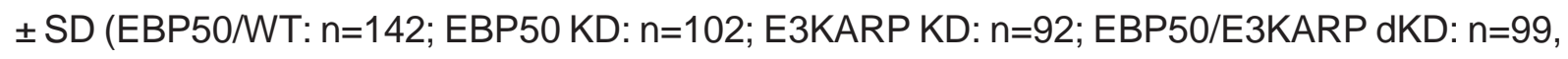
3 independent experiments). Ezrin localization was used as marker for polarized brush border formation.

Figure 5: TMIGD1 influences the dynamics of EBP50 and E3KARP. FRAP experiments for ezrin (A), EBP50 (B) and E3KARP (C). Left panels: Representative images of EGFP-Ezrin, EGFP-EBP50 and EGFP-E3KARP in apical microvilli of JEG-3 cells. Scale bars: $5 \mu \mathrm{m}$. Middle panels: Photobleaching recovery curves in cells without TMIGD1 expression (-TMIGD1) and cells with doxycycline-induced TMIGD1 expression (+TMIGD1) of EGFP-Ezrin ( $n=50$ and $\mathrm{n}=62$, - TMIGD1 and +TMIGD1, respectively), EGFP-EBP50 ( $\mathrm{n}=81$ and $\mathrm{n}=89,-$ TMIGD1 and 
+TMIGD1, respectively), and EGFP-E3KARP ( $n=143$ and $n=138$, -TMIGD1 and +TMIGD1, respectively). Error bars show mean values \pm SD. Statistical analysis was performed using Two-way Repeated Measurements ANOVA. Statistical significance: EGFP-Ezrin, not significant; EGFP-EBP50, $P=0.031$; EGFP-E3KARP, $P=0.026$. Right panels: Representative fluorescence images at different time points of FRAP experiments for EGFP-Ezrin, EGFPEBP50 and EGFP-E3KARP. Tables show recovery rates $(k)$ and half maximal recovery times (thalf) of double exponential (fast and slow) recovery curves. Scale bars: $1 \mu \mathrm{m}$.

Figure 6: TMIGD1 binding to EBP50 is regulated by phosphorylation of S162 in the carboxylate binding loop of PDZ2. (A) CoIP experiment from HEK293T cells transfected with TMIGD1 and various EBP50 phosphodeficient mutant constructs (E50/S162A, E50/S339_340A, E50/S280_302A). Note the strong increase in TMIGD1 binding in the EBP50/S162A mutant. (B) CoIP experiment from HEK293T cells transfected with TMIGD1 and EBP50 constructs (E50/WT, E50/S162A) in the presence of PMA. (C) GST pulldown with the cytoplasmic tail of TMIGD1, either WT (GST-T1) or mutants mimicking phosphorylation of Ser/Thr residues present in the PDZ domain-binding motif of TMIGD1 (GST-T1/S258D, GST$\mathrm{T} 1 / \mathrm{T} 260 \mathrm{D})$, fused to GST and in vitro translated EBP50 in the presence of recombinant ezrin/T567D. (D) ColP experiment from HEK293T cells transfected with ezrin (the $\Delta 3$ mutant of ezrin was used because ezrin/WT interacts only poorly with EBP50 in cells (Viswanatha et al., 2013), TMIGD1 and either EBP50/WT (E50/WT) or EBP50/S162A (E50/S162A). Note that TMIGD1 co-immunoprecipitation with ezrin requires EBP50 and that this interaction is enhanced when $\mathrm{S} 162$ is mutated. (E) In vitro phosphorylation/dephosphorylation of EBP50 by PKC $\alpha$ and PP1a. GST-EBP50 fusion proteins (GST-E50/WT (AA 95-268), GST-E50/S162A (AA 95-268, S162A) were incubated with recombinant PKCa either alone or followed by incubation with PP1 $1 \alpha$ in the presence of radiolabeled Y-32P-ATP. GST-JAM-A served as positive control for PKCa-mediated phosphorylation. Phosphorylation was analyzed by autoradiography (top panel), equal loading of GST fusion proteins was analyzed by Western blotting (bottom panel). (F) FRAP experiments for EBP50/S162A. Left panel: Representative 
image of EGFP-EBP50/S162A at apical microvilli of JEG-3 cells. Scale bar: $5 \mu \mathrm{m}$. Middle panel: Photobleaching recovery curves of EGFP-EBP50/S162A in cells without TMIGD1 expression (-TMIGD1, $\mathrm{n}=84$ ) and cells with doxycycline-induced TMIGD1 expression $(+$ TMIGD1, $n=71)$. Error bars show mean values \pm SD. Statistical analysis was performed using Two-way Repeated Measurements ANOVA. Statistical significance: $P=0.0007$. Right panels: Representative fluorescence images at different time points of FRAP experiments for EGFP-EBP50/S162A. The table shows recovery rates $(k)$ and half maximal recovery times (thalf) of double exponential (fast and slow) recovery curves. Scale bar: $1 \mu \mathrm{m}$.

Figure 7: TMIGD1 mediates trans-homophilic interaction. (A) Cell aggregation assays of HEK293T cells either untransfected (WT) or transfected with empty vector (pcDNA3), TMIGD1NT, TMIGD1/A5, JAM-A (negative control) or CAR (positive control). Statistical analysis was performed using unpaired student's t-test, data is presented as means \pm SEM (five independent experiments). (B) ColP experiment from HEK293T cells transfected with untagged TMIGD1 (TMIGD1/WT, TMIGD1/A5, TMIGD1/DCP, lacks cytoplasmic part) together with tagged TMIGD1 (Flag-TMIGD1-EGFP, Flag-TMIGD1-EGFP-JAM-A (cytoplasmic part of TMIGD1 replaced by cytoplasmic part of JAM-A) as indicated. Asterisks indicate lg heavy chains. (C) Bead aggregation assay with fluorescently labeled beads either uncoated or coated with FC fusion proteins of JAM-B or JAM-C (negative controls) or TMIGD1. Left panel: Representative IF images. Scale bars: $20 \mu \mathrm{m}$. Right panel: Quantification of bead aggregation. Quantification was performed using Ordinary one-way ANOVA with Dunnett's multiple comparison. Data is presented as means \pm SEM (3 independent experiments). ${ }^{* * * *} \mathrm{P}<0.0001$.

Figure 8: Model of TMIGD1 localization and function at microvilli. (A) Intermicrovillar adhesion complexes in epithelial cells. Microvilli (MV) contain a protocadherin-based intermicrovillar adhesion complex (IMAC) at their tips. Protocadherins CDHR2 and CDHR5 interact in a trans-heterophilic manner. MV tip localization of the IMAC is regulated by Myo7B associated with CDHR2 or CDHR5 through USHC1. The IMAC regulates microvilli packing. 
The present study suggest a second adhesion complex localized at the subapical region of microvilli. This complex is based on trans-homophilic interactions of the IgSF member TMIGD1 which interacts with the two scaffolding proteins EBP50 and E3KARP. (B) Hypothetical model on the role of the TMIGD1-based adhesion complex. The following model incorporates the observations presented in this manuscript into the existing model proposed by Viswanatha and colleagues (Viswanatha et al., 2014). MV tip: Ezrin localized at the MV tips is phosphorylated at T567 by an ezrin kinase (EzK), either lymphocyte oriented kinase (LOK) or the related sterile 20-like kinase (SLK) and/or Mammalian STE20-like protein kinase 4 (MST4). T567phosphorylated ezrin adopts the open conformation allowing simultaneous binding to the plasma membrane (through the $\mathrm{N}$-terminal FERM domain) and $\mathrm{F}$-actin (through the $\mathrm{C}$-terminal C-ERMAD domain). MV base: Through its FERM domain, active ezrin binds to the ezrinbinding region of EBP50 triggering the open conformation of EBP50 thereby enabling accessibility both of its two PDZ domains and of its C-terminal region which harbors the PP1 $\alpha$ binding site. Ezrin-bound EBP50 is now able to bind PP1a which dephosphorylates S162 in PDZ domain 2 of EBP50 thereby promoting its interaction with TMIGD1. EBP50-bound PP1a dephosphorylates ezrin at T567 resulting in the closed conformation and ezrin inactivation. As a consequence, ezrin dissociates from EBP50 which adopts its closed conformation and dissociates from TMIGD1. Inactive ezrin and inactive EBP50 can undergo another cycle of activation and deactivation. Adapted from (Viswanatha et al., 2014).

\section{Expanded View / Supplemental Figure Legends}

\section{Suppl. Figure S1: Statistical analysis of TMIGD1 expression in intestinal epithelial cell}

lines. Caco- $2_{\text {Bbe1 }}$ cells (left panel) and T84 cells (right panel) were cultured on $0.4 \mu \mathrm{m}$ polycarbonate filters to allow differentiation. At the indicated time points cells were stained with

TMIGD1 antibodies. TMIGD1-positive cells were counted by visual inspection. TMIGD1positive Caco-2 $2_{\mathrm{Bbe} 1}$ cells were quantified in three independent experiments in which at least 
three fields of view each containing between 81 and 122 cells were analyzed (average fraction of TMIGD1-positive cells at day 24 post confluency: 6.2\%, 5.7\%, 5.9\%).

Suppl. Figure S2: Characterization of LS174T-W4 cells. (A) EBP50 and E3KARP co-localize with TMIGD1 at polarized brush borders of LS174T-W4 cells. Cells transfected with untagged TMIGD1 and either EGFP-EBP50 or Myc-E3KARP as indicated were either left uninduced (Dox.) or were induced (+Dox.) to develop a brush border. Cells were stained with antibodies against TMIGD1 and the Myc-tag and analyzed by IF microscopy. EGFP-EBP50 was detected by its GFP fluorescence. Scale bars: $5 \mu \mathrm{m}$. (B) EBP50 KD LS174T-W4 cells, E3KARP KD LS174T-W4 cells and EBP50/E3KARP double KD LS174T-W4 cells were analyzed by Western blotting for the expression of EBP50 and E3KARP (left panels) and for the expression of microvilli components ezrin, P-T567-ezrin (pERM) and Eps8 (right panels). (C) LS174T-W4 cells (LS174/WT) and EBP50/E3KARP double KD LS174T-W4 cells (LS174/E50-E3K dKD) were analyzed by EM. Note that EBP50/E3KARP double KD LS174T-W4 cells form a microvilli-containing brush border. Scale bars: 2 mm. (D) EBP50/E3KARP double KD LS174TW4 cells induced with doxycycline were stained for F-actin and Eps8 as indicated. Note that F-actin and Eps8 are enriched at polarized brush borders. Scale bars: $5 \mu \mathrm{m}$.

Suppl. Figure S3: Characterization of JEG-3 cells with inducible expression of TMIGD1. Left panel: Western blot analysis of ectopic TMIGD1 expression in JEG-3 cells. Left blot: JEG3 cells stably transfected with a lentiviral expression vector allowing inducible expression of TMIGD1 (plnducer21) were treated with doxycycline (Dox.) for $24 \mathrm{~h}$ and analyzed with antibodies against TMIGD1. Right Blot: Cells were treated for different time periods with doxycycline as indicated and analyzed with antibodies against TMIGD1. Right panel: IF analysis of TMIGD1 localization in JEG-3 cells. Cells were either left uninduced (-Dox.) or were induced (+Dox.) to express TMIGD1. Cells were stained with antibodies against TMIGD1 and ezrin as indicated. Scale bars: $5 \mu \mathrm{m}$. 
Figure 1

A

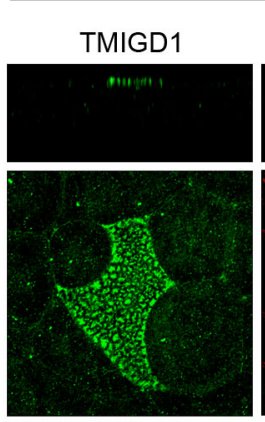

B

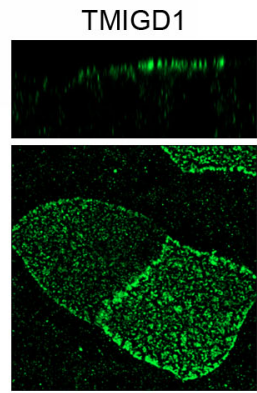

TMIGD1

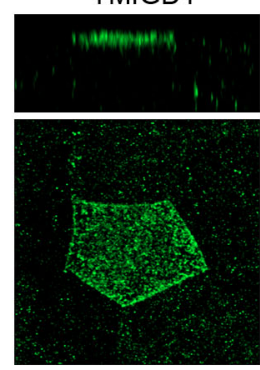

D

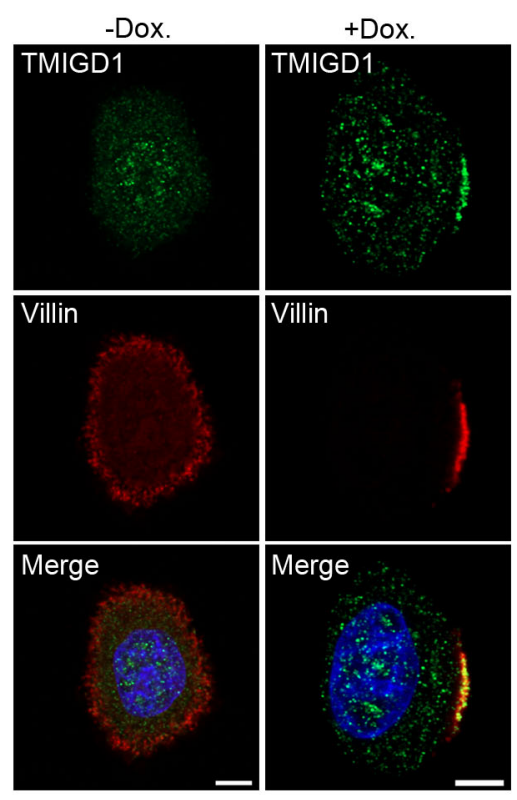

F

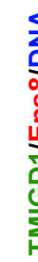

Caco-2

ZO-1

Ezrin

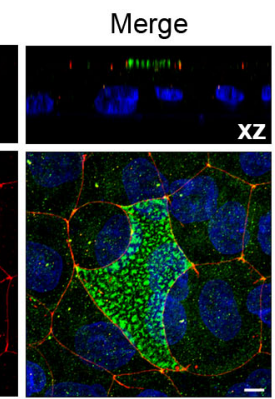

Merge

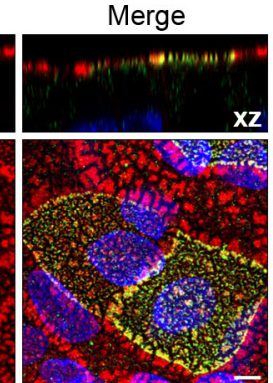

Merge

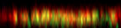

xz

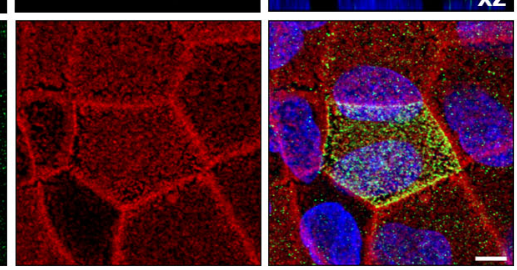

E

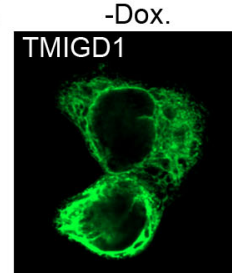

Ezrin

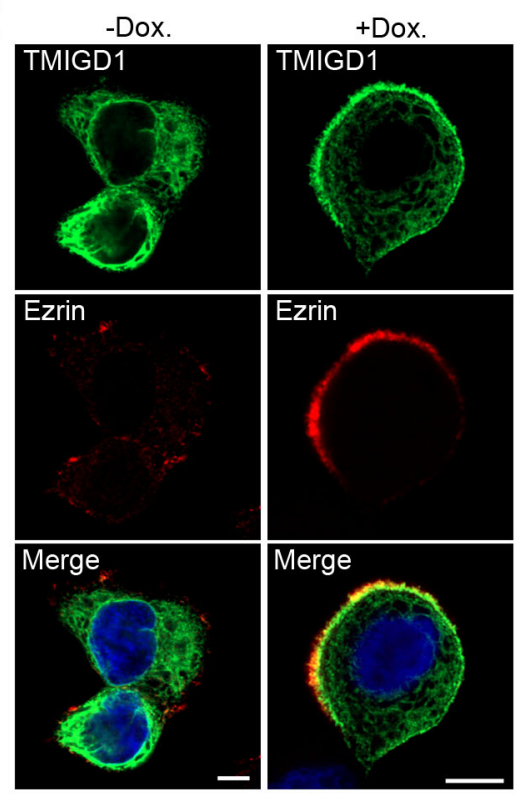

C
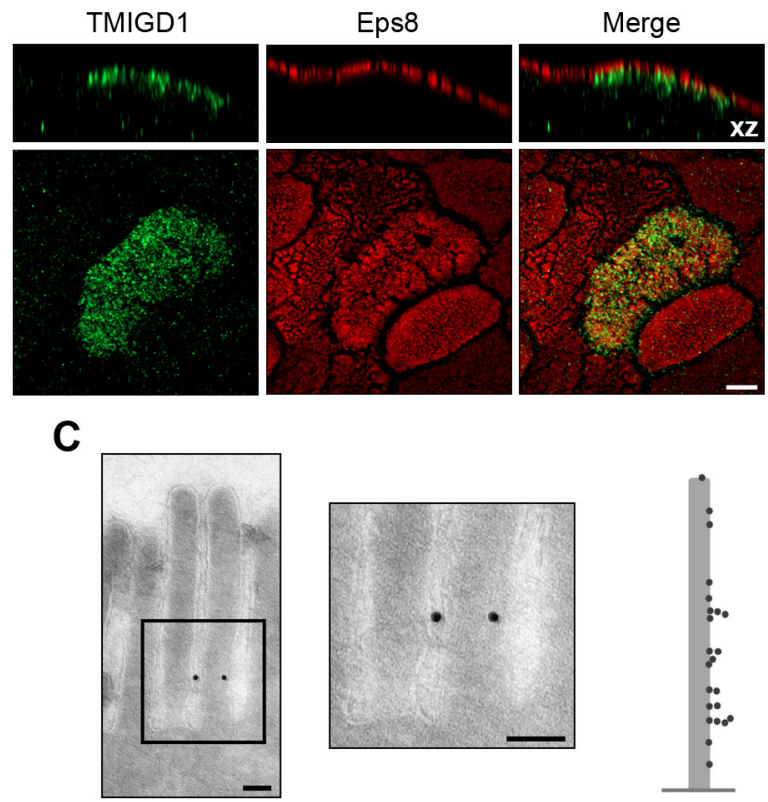

$-$
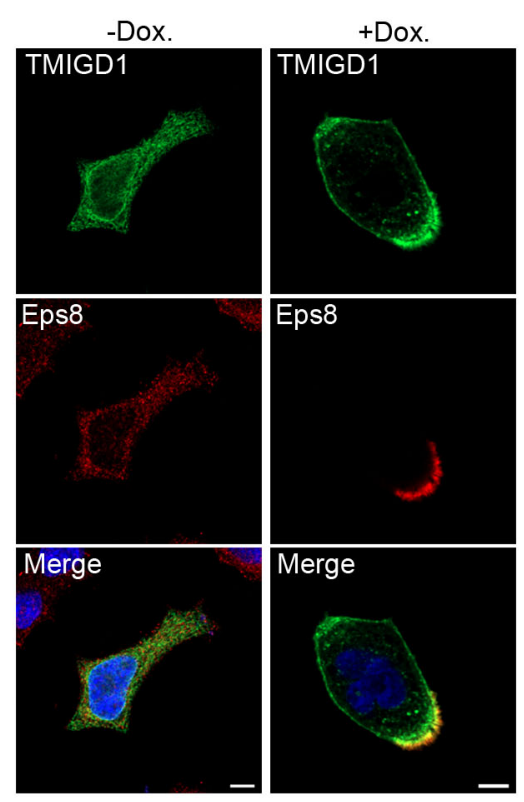

G
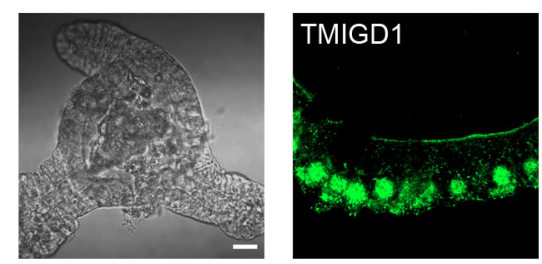

Merge

Villin

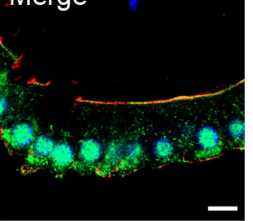


Figure 2

A

\section{E3KARP}

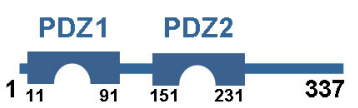

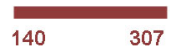

Y2H clone

D

Trfet.

E3KARP

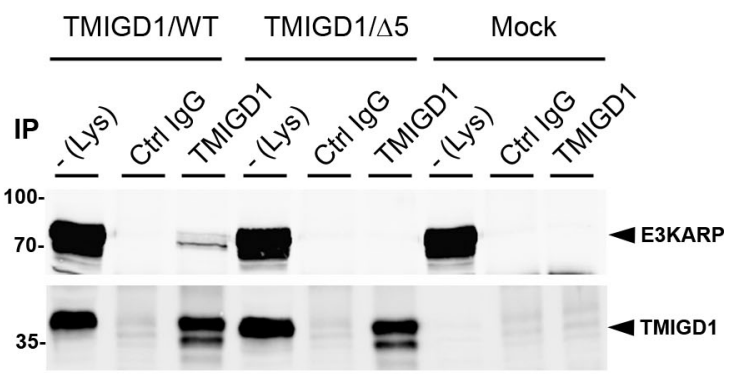

C

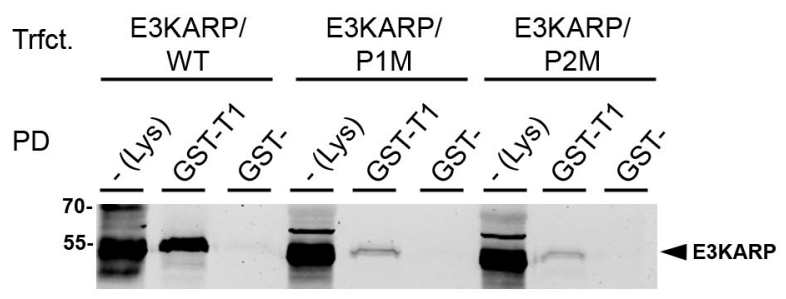

Trfct. E3KARP/ E3KARP/ E3KARP/

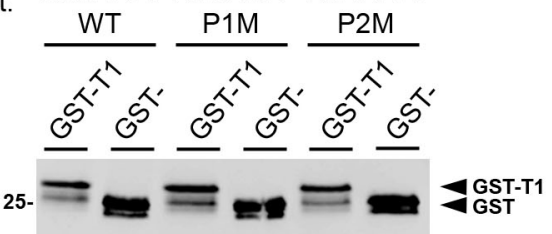

Trfct.

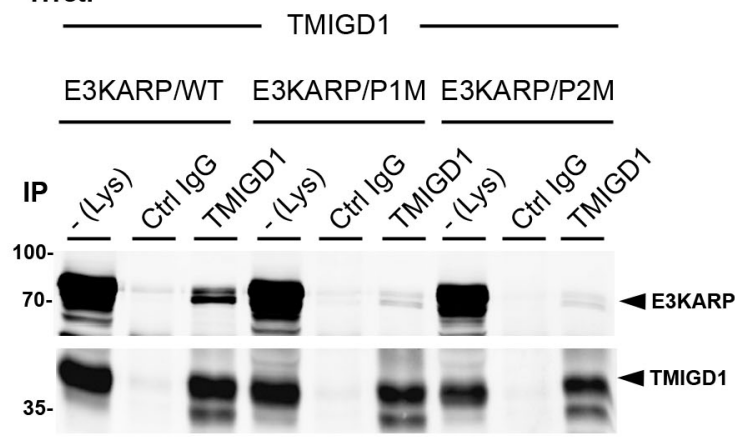


Figure 3

A

Trfct.

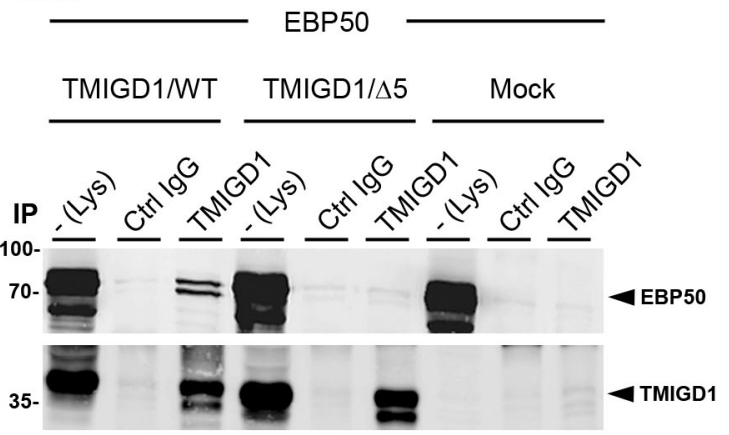

B

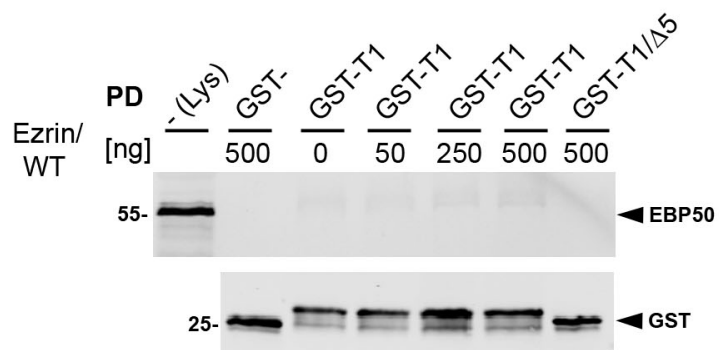

C

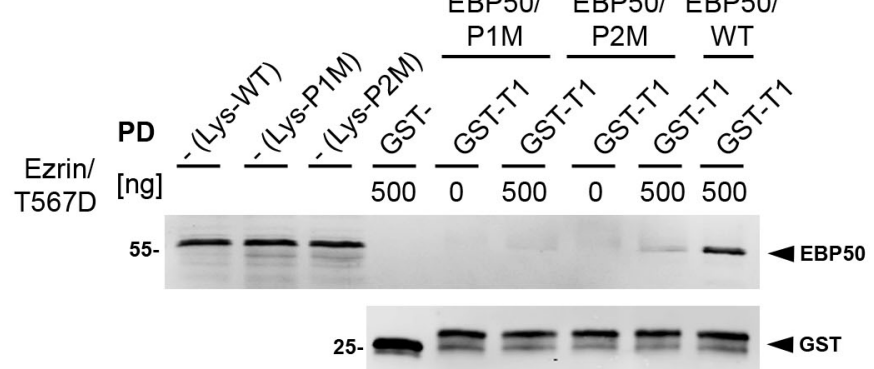

Trfet.

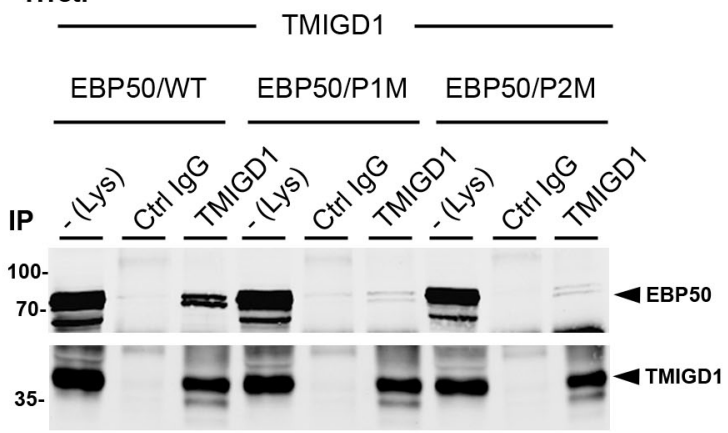

D

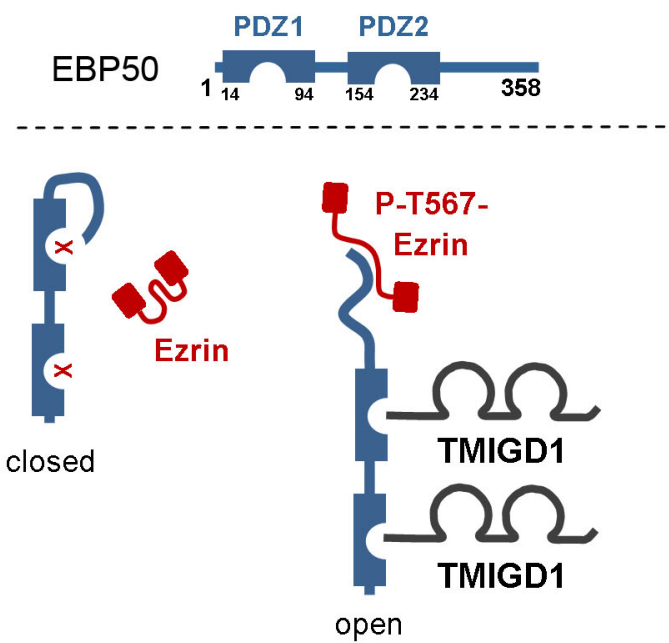


Figure 4

A

TMIGD1/WT
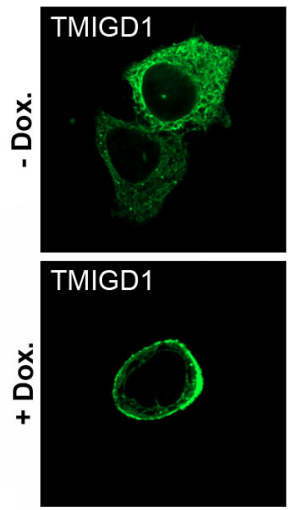

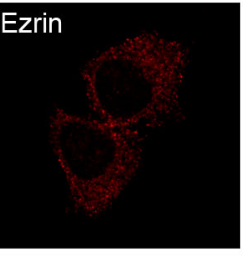

Ezrin

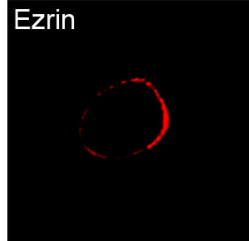

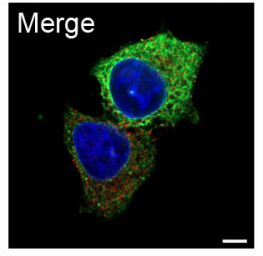

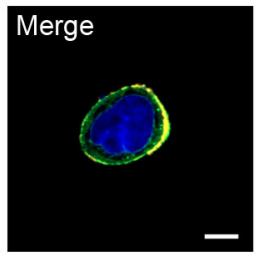

TMIGD1/A5
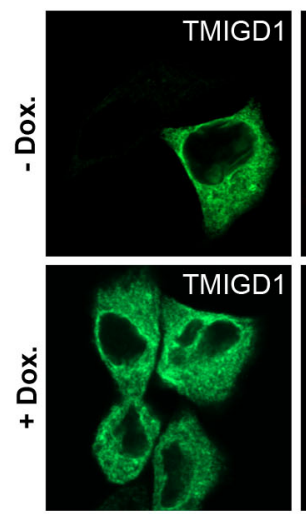
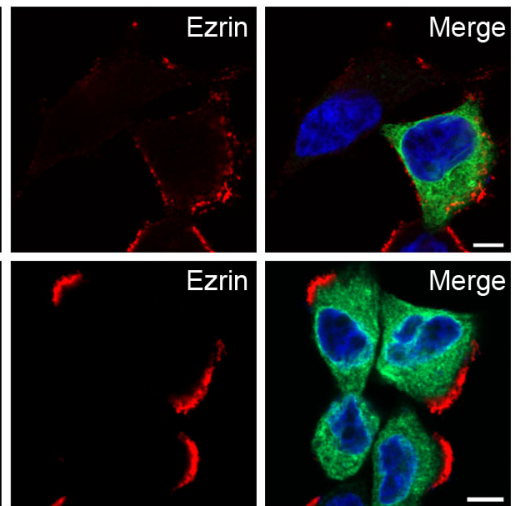

B
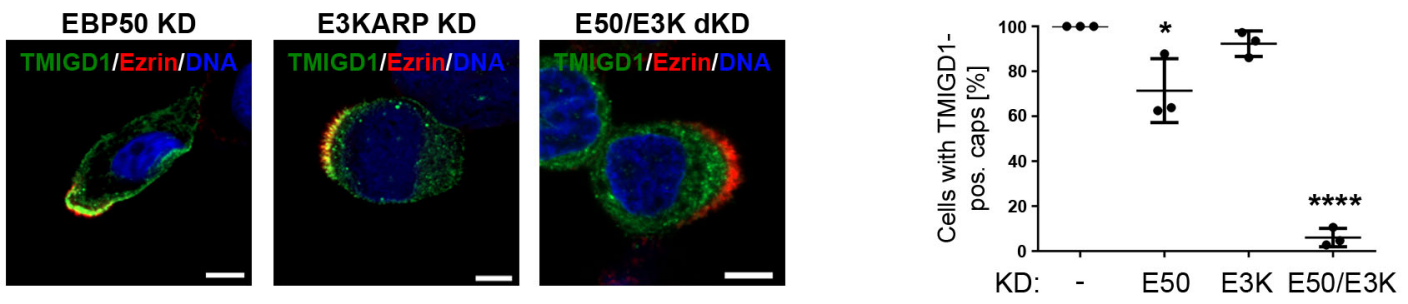


\section{Figure 5}

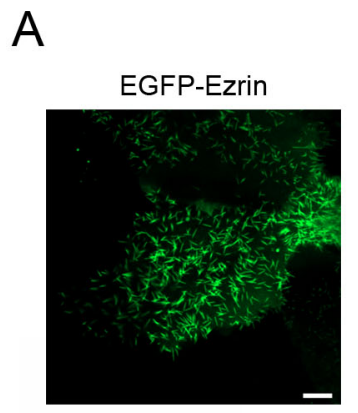

B

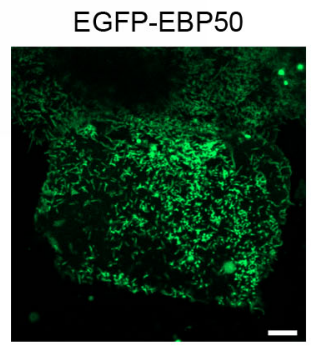

C

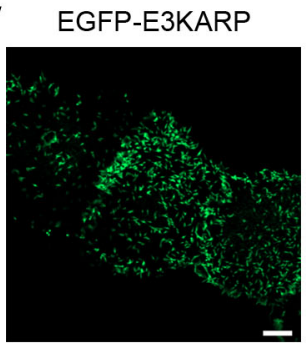

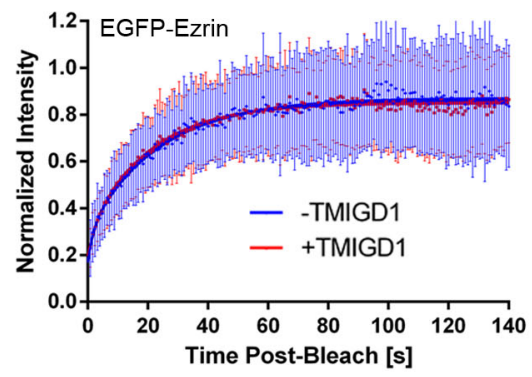
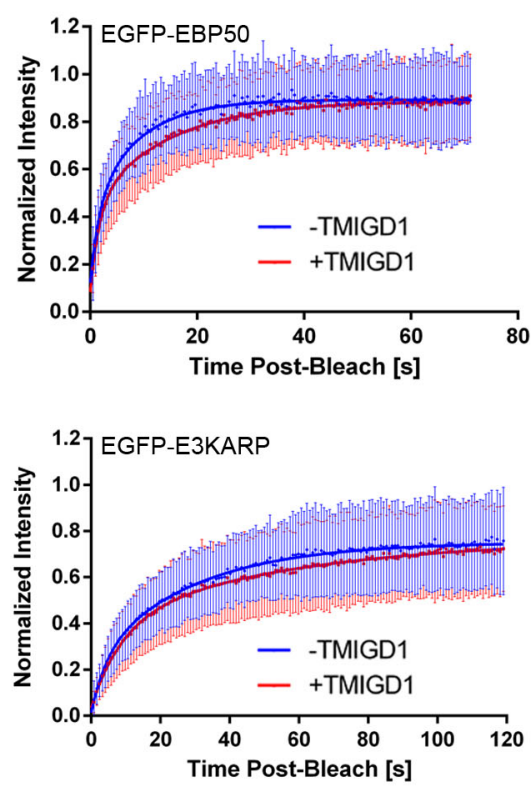

Seconds Post-Bleach

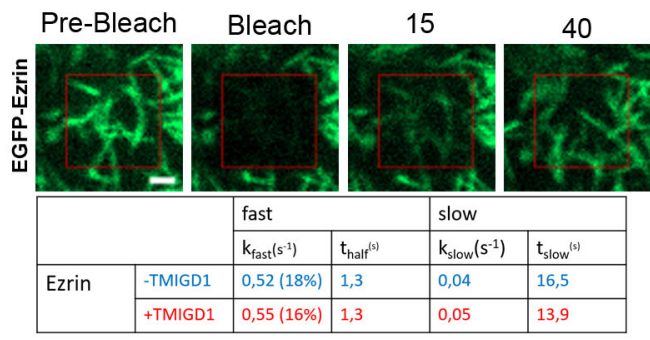

Seconds Post-Bleach

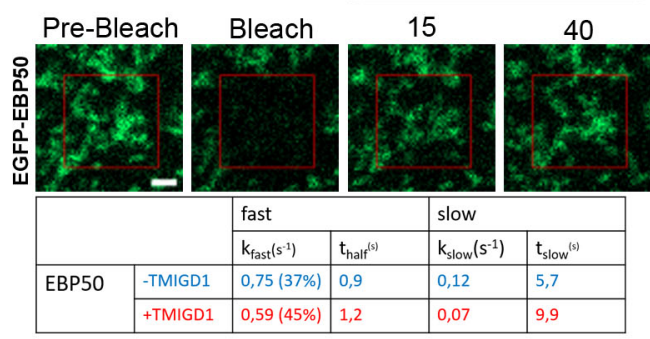

Seconds Post-Bleach

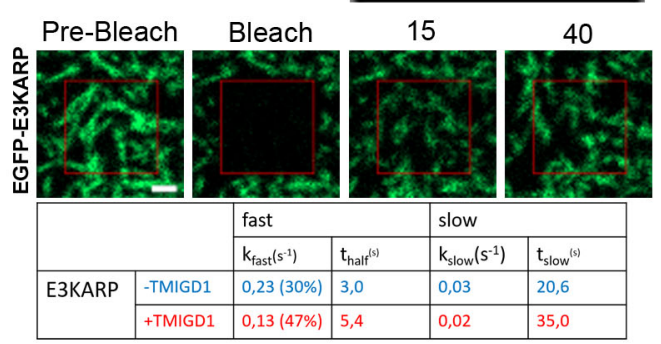




\section{Figure 6}

A

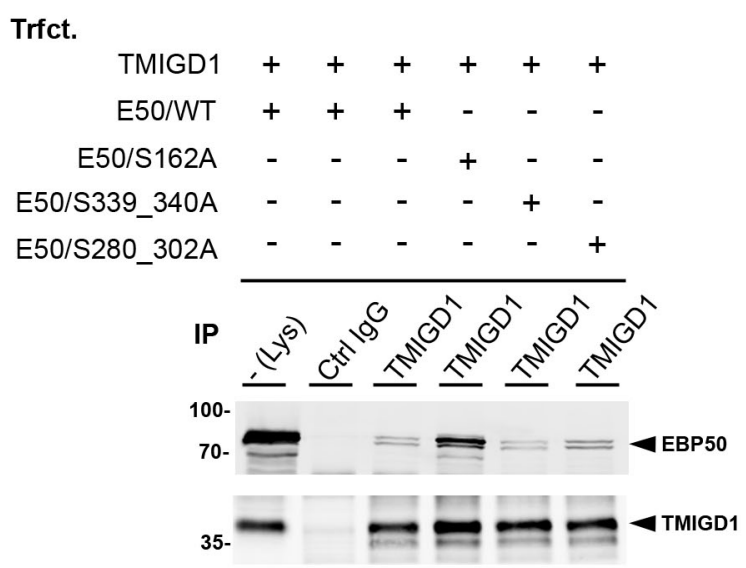

C

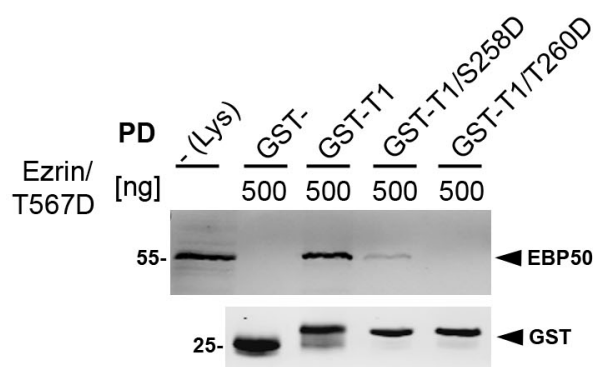

E

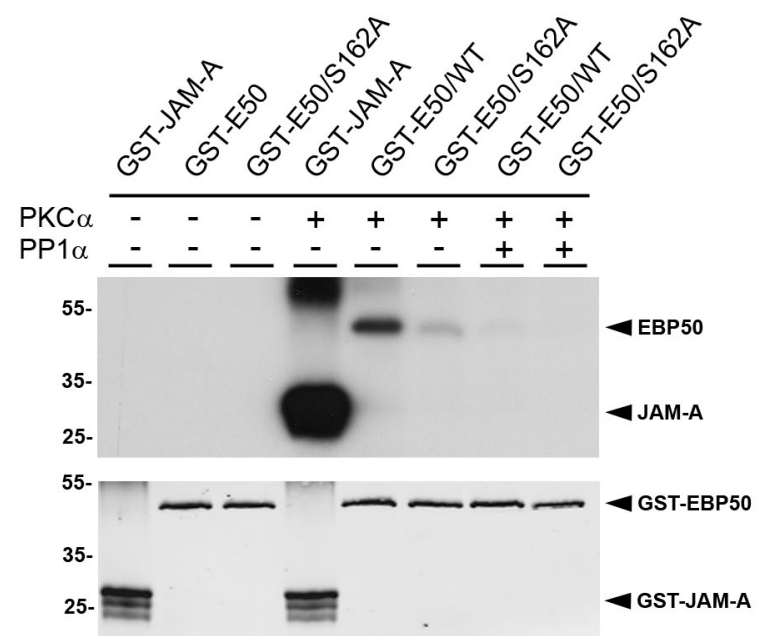

F
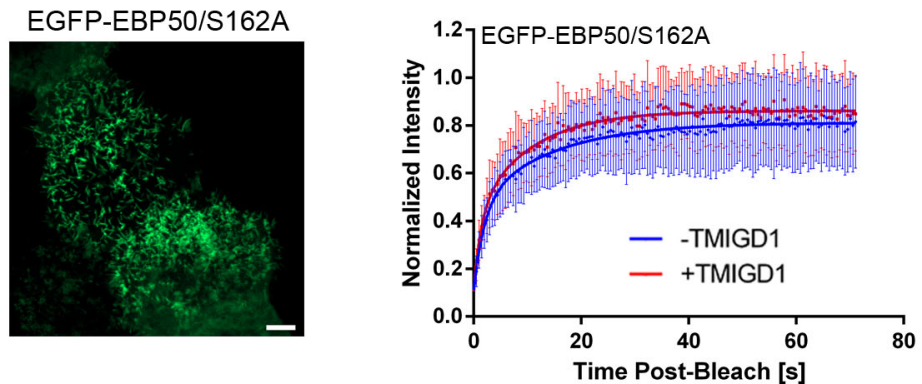

Trfet.

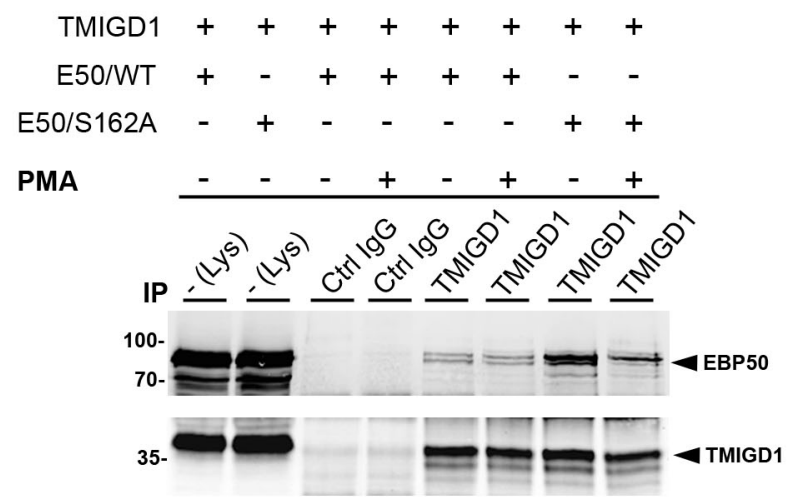

Trfet.

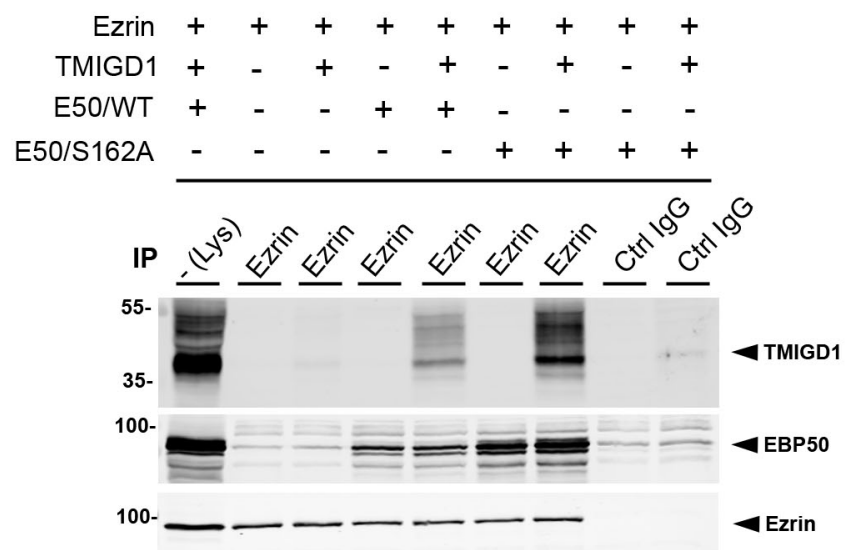


Figure 7

A

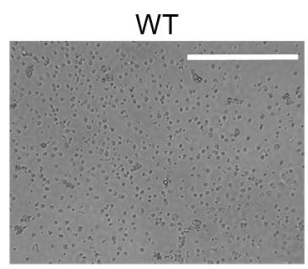

TMIGD1/A5

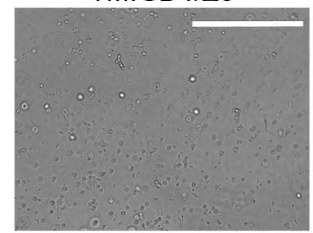

B

Trfet.

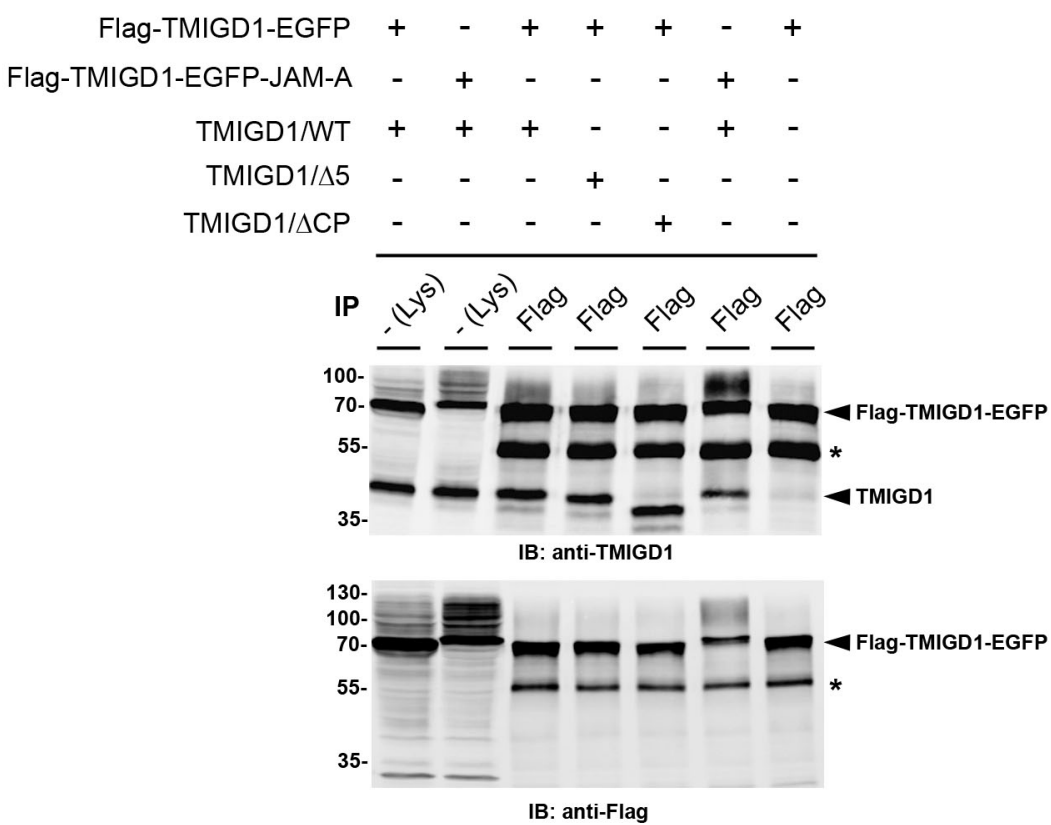

TMIGD1

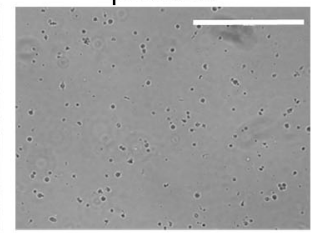

JAM-A

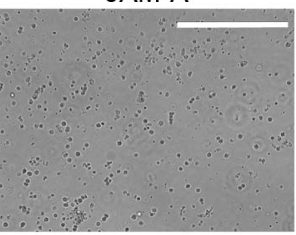

CAR

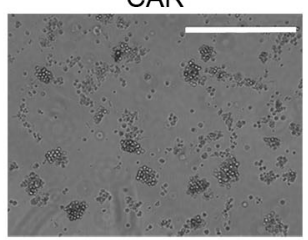

C

C

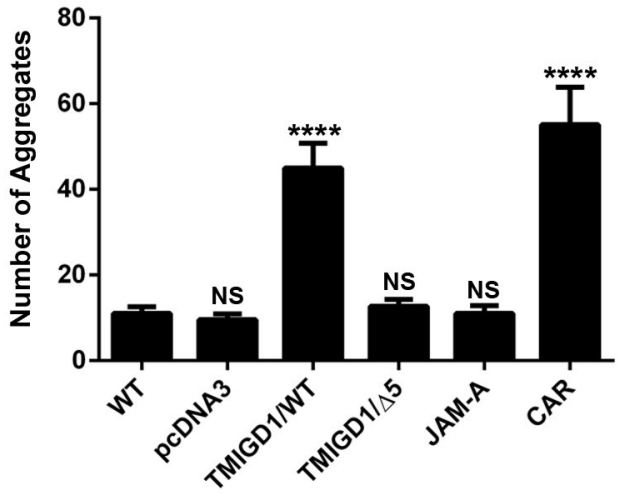

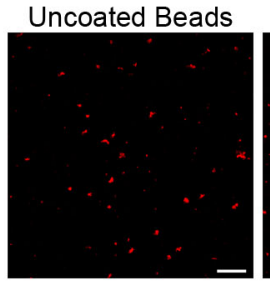

JAM-C

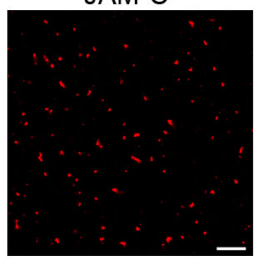

TMIGD1
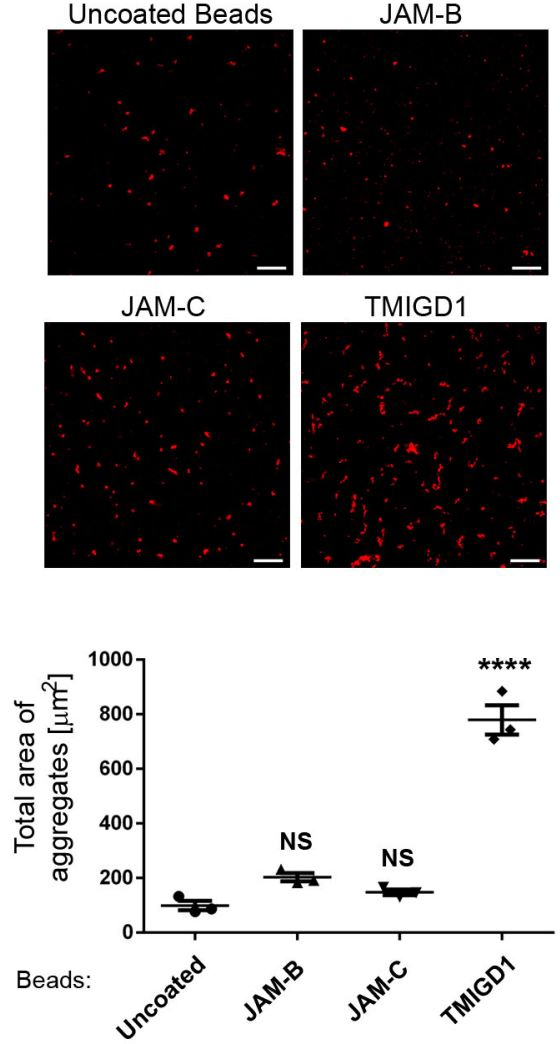


\section{Figure 8}

A
B

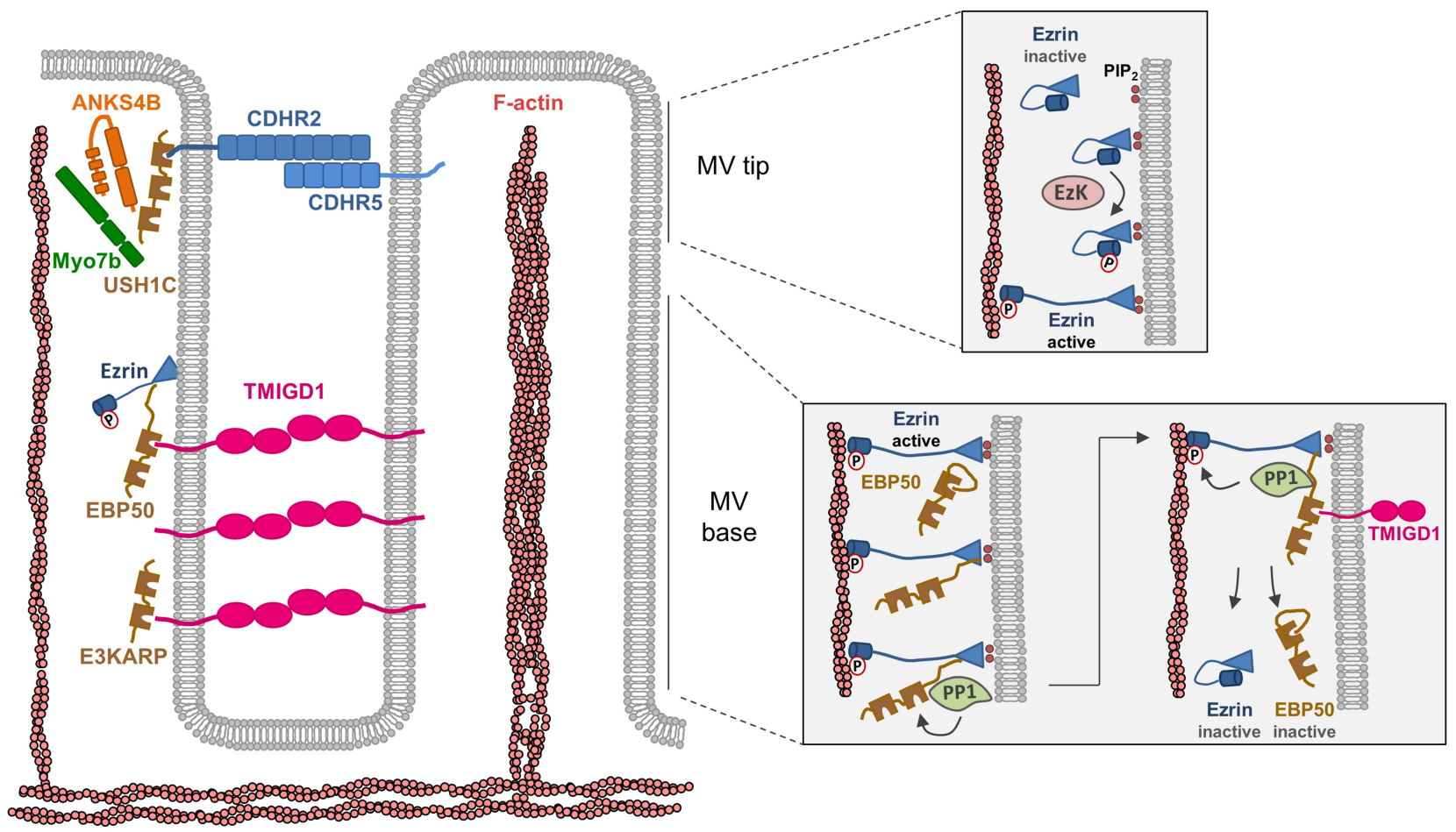




\section{Suppl. Figure S1}

A

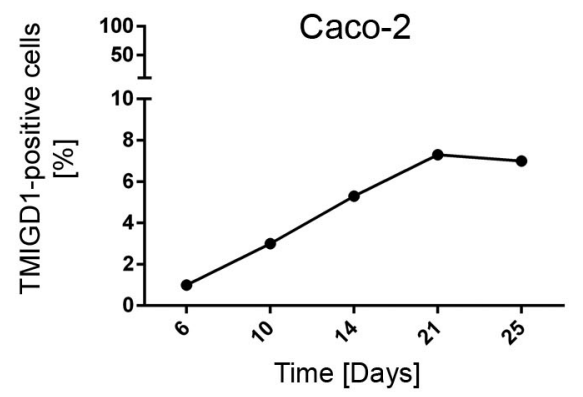

B

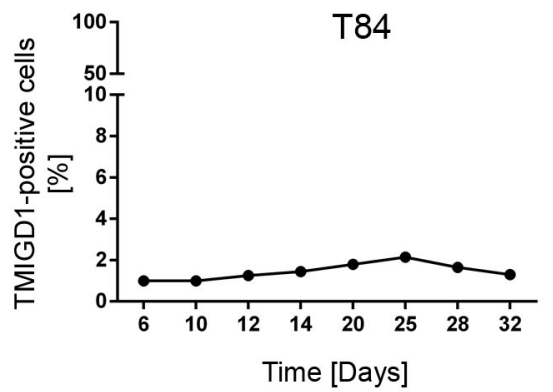




\section{Suppl. Figure S2}

A
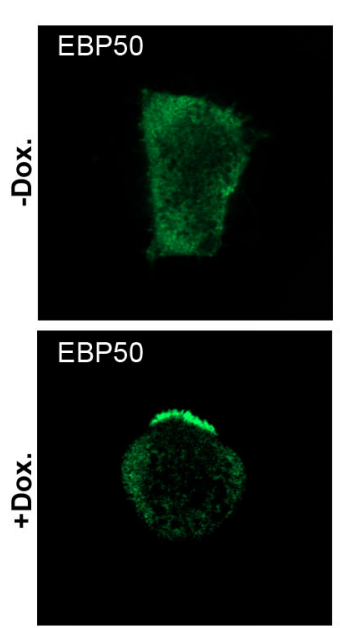

EBP50 + TMIGD1
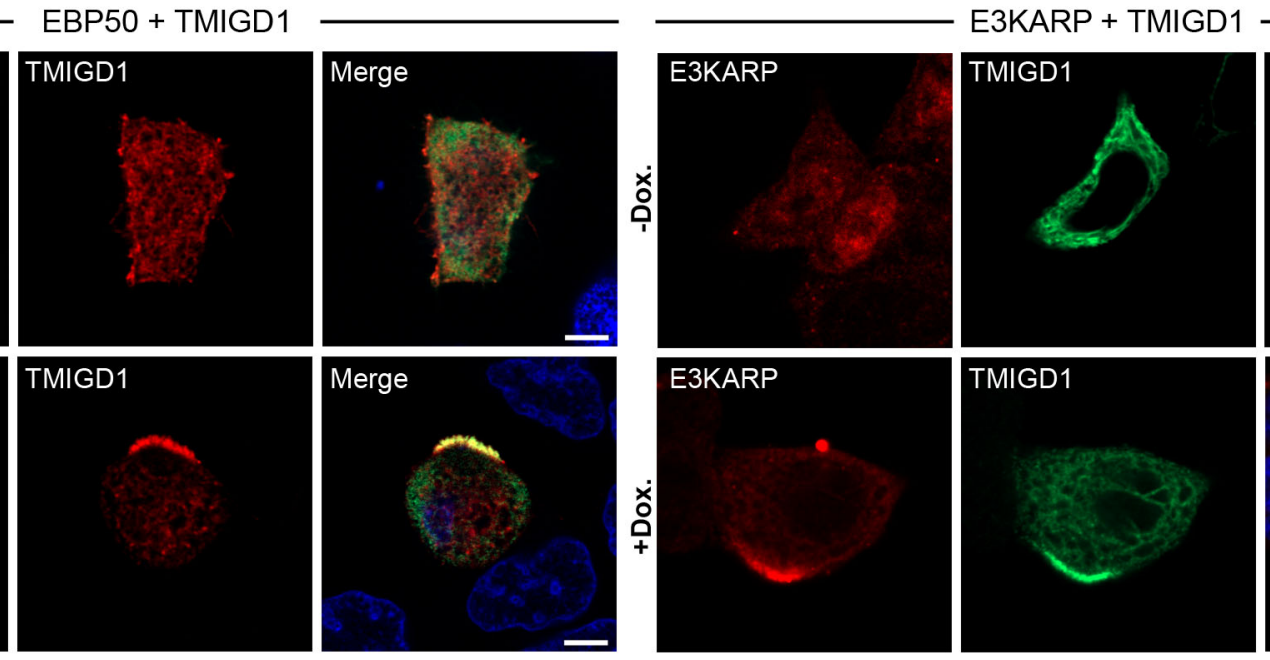

B

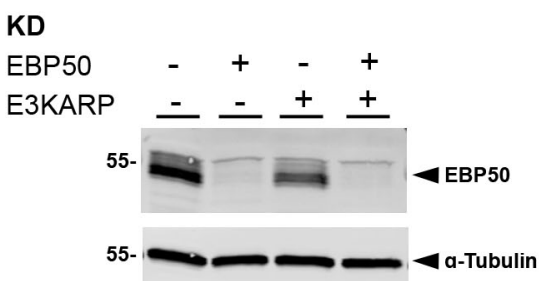

KD

EBP50

E3KARP - - +

KD

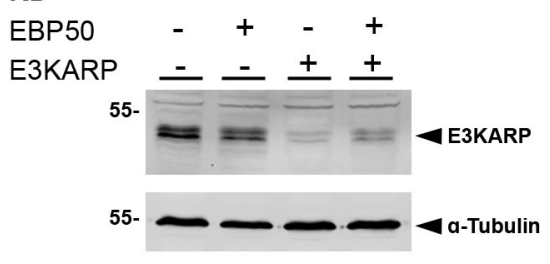

C
LS174/WT

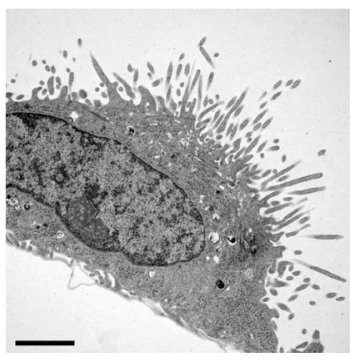

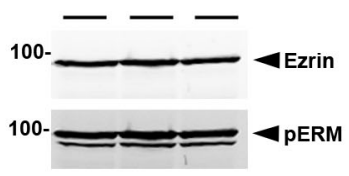
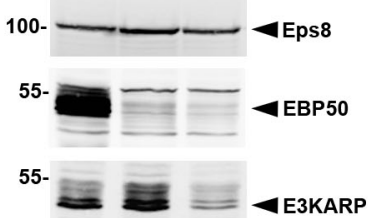

55- $\longrightarrow$ a-Tubulin

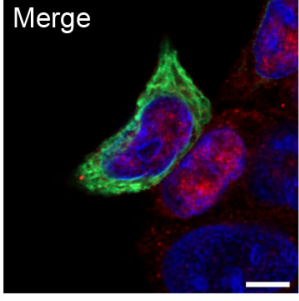

Merge

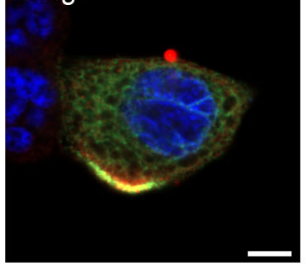

D EBP50/E3KARP dKD

\begin{tabular}{|c|c|c|c|}
\hline EBP50 & F-Actin & Eps8 & Merge \\
\hline E3KARP & F-Actin & Eps8 & Merge \\
\hline
\end{tabular}

LS174/E50-E3K dKD

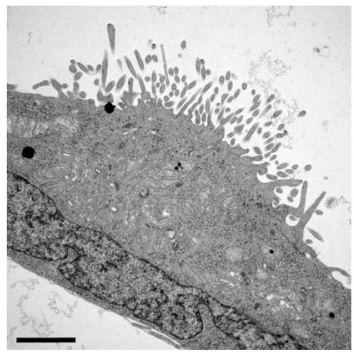




\section{Suppl. Figure S3}
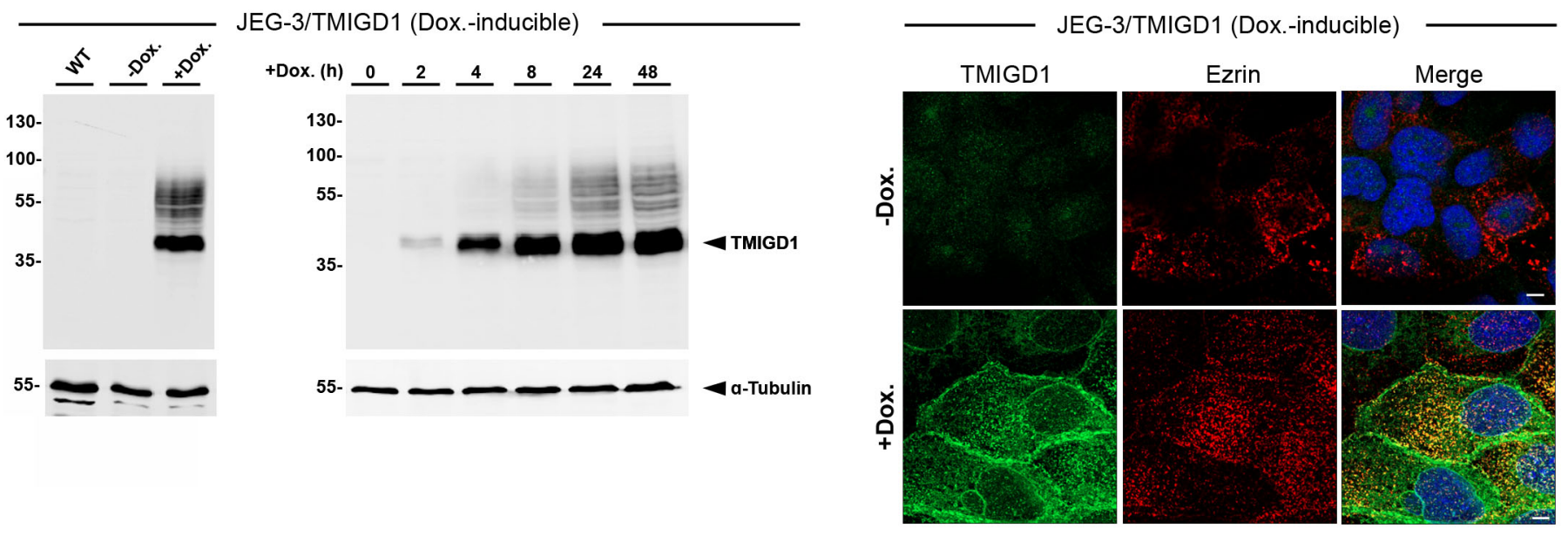